\title{
Samuel Toledano
}

$$
\text { (editor) }
$$

\section{Mucho por descubrir}

Panorama mundial del periodismo de investigación

CAC, Cuadernos Artesanos de Comunicación / 139

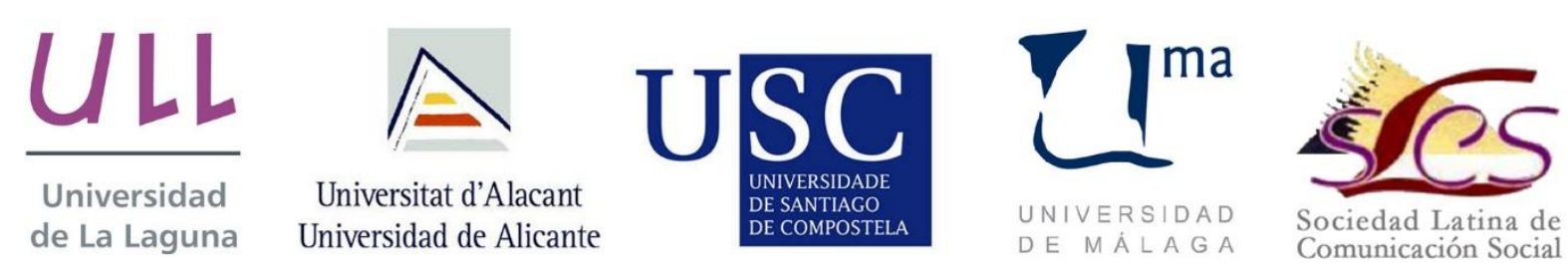




\section{Cuadernos Artesanos de Comunicación \# 139 \\ Coordinador editorial: José Manuel de Pablos [ jpablos@ull.edu.es ]}

Comité Científico

Presidencia: José Luis Piñuel Raigada (UCM)

Secretaría: Concha Mateos (URJC)

- José Antonio Meyer (Benemérita Universidad Autónoma de Puebla)

- Ramón Reig (Universidad de Sevilla, US)

- Miquel Rodrigo Alsina (Universidad Pompeu Fabra, UPF)

- Xosé Soengas (Universidad de Santiago de Compostela, USC)

- José Luis Terrón (Universidad Autónoma de Barcelona, UAB)

- José Miguel Túñez (Universidad de Santiago, USC)

- Victoria Tur (Universidad de Alicante, UA)

- Miguel Vicente (Universidad de Valladolid, UVA)

- Ramón Zallo (Universidad del País Vasco, UPV-EHU)

- Núria Almiron (Universidad Pompeu Fabra, UPF)

- Francisco Campos Freire (Universidad de Santiago de Compostela)
- José Cisneros (Benemérita Universidad Autónoma de Puebla, BUAP

- Bernardo Diaz Nosty (Universidad de Málaga, UMA)

- Carlos Elías (Universidad Carlos III de Madrid, UC3M)

- Paulina B. Emanuelli (Universidad Nacional de Córdoba, UNC)

- José Luis González Esteban (Universitas Miguel Hernández.

- Marisa Humanes (Universidad Rey Juan Carlos, URJC)

- Juan José Igartua (Universidad de Salamanca, USAL)

- Octavio Islas (Universidad de los Hemisferios, Ecuador)

- Xosé López (Universalidad de Santiago de Compostela, USC)

- Maricela López-Ornelas (Universidad Autónoma de Baja California)

- Javier Marzal (Universidad Jaume I, UJI)

* Queda expresamente autorizada la reproducción total o parcial de los textos publicados en este libro, en cualquier formato o soporte imaginables, salvo por explícita voluntad en contra del autor o autora o en caso de ediciones con ánimo de lucro. Las publicaciones donde se incluyan textos de esta publicación serán ediciones no comerciales y han de estar igualmente acogidas a Creative Commons. Harán constar esta licencia y el carácter no venal de la publicación.

\section{(c) $\odot \circledast$}

ste libro y cada uno de los capitulos que contiene, así como las imágenes incluidas, si no se indica lo contrario, se encuentran bajo una Licencia Creative Commons Atribución-No Comercial-Sin Derivadas 3.0 Unported. Puede ver una copia de esta licencia en http://creativecommons.org/licenses/by-nc-nd/3.0/ Esto significa que Ud. es libre de reproducir y distribuir esta obra, siempre que cite la autoría, que no se use con fines comerciales o lucrativos y que no haga ninguna obra derivada. Si quiere hacer alguna de las cosas que aparecen como no permitidas, contacte con los coordinadores del libro o con el autor del capítulo correspondiente. * La responsabilidad de cada texto es de su autor o autora. 
Samuel Toledano (editor)

Nerea Mancisidor y Marta Rodríguez (coordinadoras)

Alumnos de Periodismo de investigación (2015-2016) de la ULL (autores)

\section{Mucho por descubrir}

Panorama mundial del periodismo de investigación

CAC, Cuadernos Artesanos de Comunicación / 139

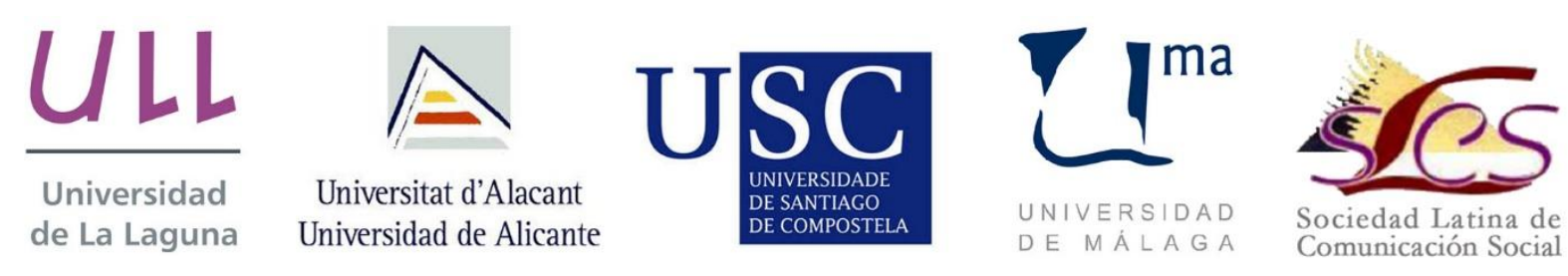


$139^{\circ}$ - Mucho por descubrir. Panorama mundial del periodismo de investigación- Samuel Toledano (editor) Nerea Mancisidor y Marta Rodríguez (coordinadoras)

Alumnos de Periodismo de investigación (2015-2016) de la Universidad de La Laguna (autores)

Precio social: 4,55€ | Precio en librería: 5,90€

Editores de la colección: Javier Herrero y Milena Trenta

Diseño: F. Drago

Ilustración de portada: Sin título, Nerea Mancisidor (2017)

Imprime y distribuye: F. Drago. Andocopias S. L.

c/ La Hornera, 41. La Laguna. Tenerife.

Teléfono: 922250554 | fotocopiasdrago@telefonica.net

Edita: Sociedad Latina de Comunicación Social - edición no venal

- La Laguna (Tenerife), 2017 - Creative Commons http://www.revistalatinacs.org/09/Sociedad/estatutos.html

http://www.revistalatinacs.org/068/cuadernos/artesanos.html

Protocolo de envío de manuscritos con destino a C.A.C.:

http://www.revistalatinacs.org/068/cuadernos/protocolo.html

Descargar pdf:

http://issuu.com/revistalatinadecomunicacion/docs/cac139

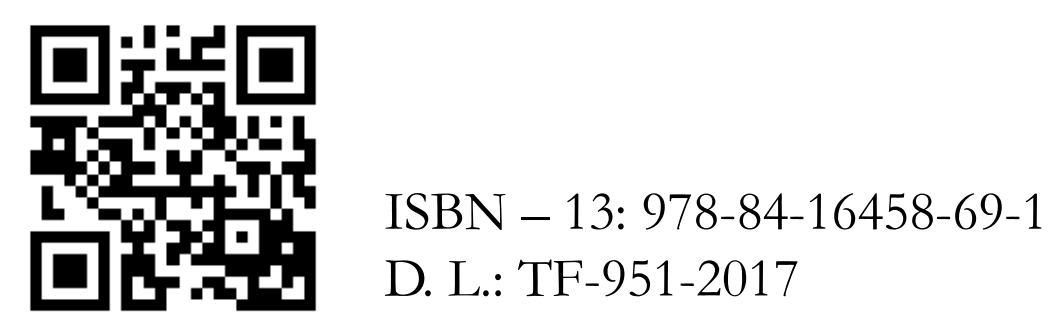




\section{Resumen}

Este libro es fruto de un trabajo colectivo de la clase de periodismo de investigación (2015-2016) de la Universidad de La Laguna. En él se traza en un formato de presentación, algunos elementos de la situación actual de una de las disciplinas periodísticas más relevantes. La importancia del periodismo de investigación para el fortalecimiento de las sociedades democráticas tiene, sin embargo, grandes retos por delante. Los datos y declaraciones recogidas a profesionales, informes y normativas de diferentes países ponen de manifiesto la delicada situación en la que viven muchos periodistas en el mundo.

\section{Palabras clave}

España, periodismo de investigación, Universidad de La Laguna

\section{Abstract}

This book was written by investigative journalism students (2015-2016) at University of La Laguna. This work uses a visual format in order to show some relevant elements of one of the most important journalism discipline. Investigative journalism plays a key role in the enhancement of democratic societies, but it still has some challenges to face. All the collected data and testimonies from professionals, reports and laws from different countries portrait the delicate situation of many journalists all over the world.

\section{Key words}

Spain, investigative journalism, University of La Laguna 


\section{Autores}

\section{Nerea Mancisidor Nóbrega \\ Marta Rodríguez Leiton \\ (coordinadoras)}

Ilia Abdel Majid Hassan Andrea Abreu López

Rubén Asensio González

Esmeralda Yelenia Beltrán Correa

Fabio Alberto Benitez Santana

Luis Fernando Cabeza López

Antonio Cabrera Alonso

Fabio Cordero Travieso

Ainoha Cruz Gómez

Samuel Díaz Salguero

Edson Miguel Dietrich Flores

Pablo Fanjul González

María Daniela García Hernández

Silvia González Nicolás

Alejandra González Noda

Raquel Guillán

Óliver Hernández Barroso
Virginia Hernández Martín

Laura Hernández Ojeda

Carlos Javier Hernández Rodríguez

Yariksa Herrero González

Cristina Jerez Jiménez

Víctor Jorge García

Jorge Marqués Yanes

Laura Marrero Bacallado

Andrea Martín Corchero

María Medina Rodríguez

José Mendoza Figueroa

Andrea Millán Moreno

Claudia Molina

Lucía Mora Delgado

Adrián Morales Pinto

Julia Moranz Gobea

Stephany Mariana de Oliveira González
Thais Palenzuela Pérez

Virginia Pérez Tenoury

Judith Ramón Afonso

Jana Liova Recio del Rosario

Alba Rodríguez Grillo

Patricia María Rodríguez Losada

Adriana Rodríguez Sánchez Cerrudo

Borja Romero González

Milagros Natalia Ruiz González

Darío Ruiz Molina

Ivory Samos Acosta

Sara Sánchez Rodríguez

Amanda Santana Rodríguez

Claudia Simón Febles

Nira Sosa Santana

Fátima del Cristo Tapia Adrián

Vanessa Carolina Tineo Espina

Naomi Vera Hernández 

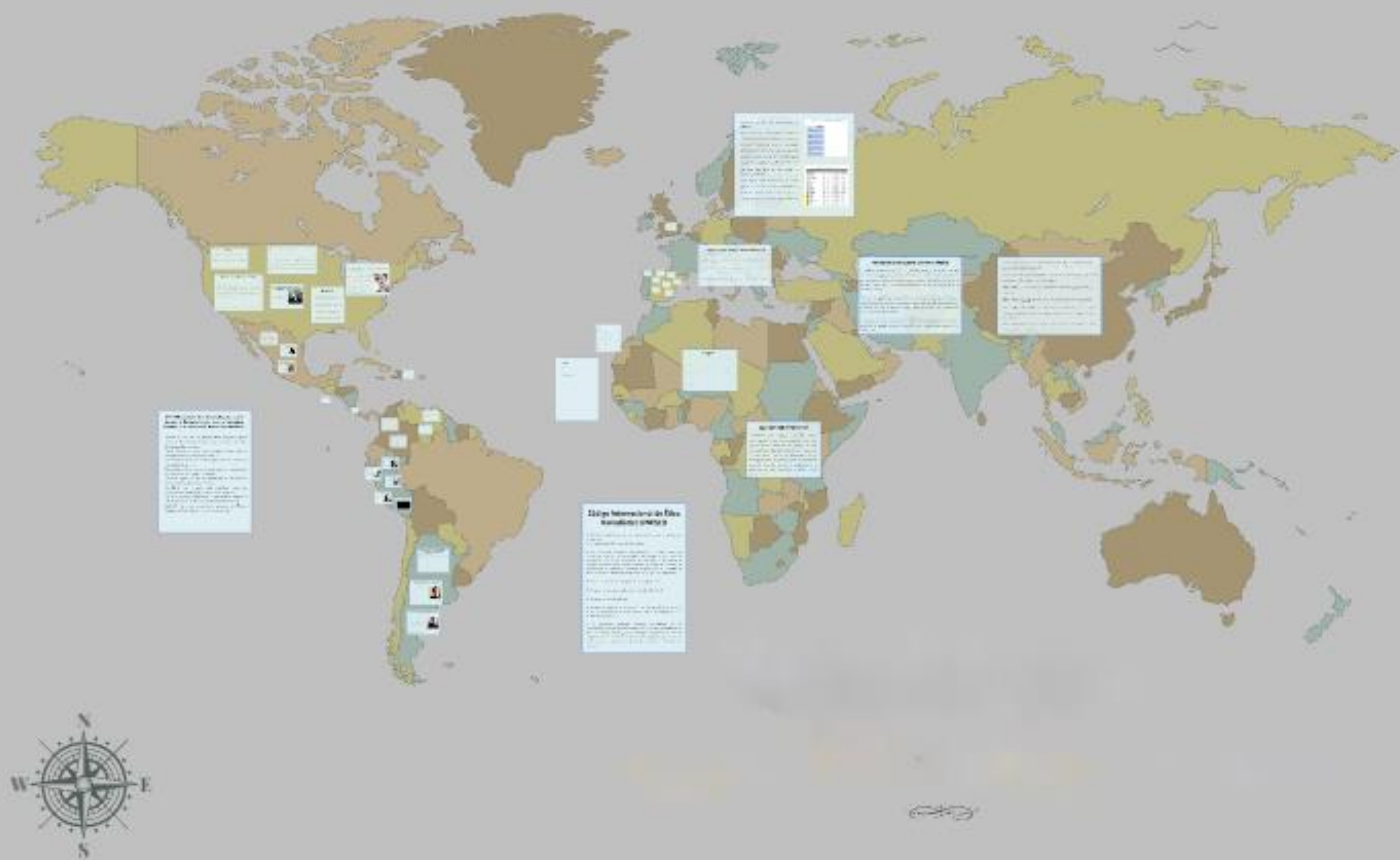


\section{Mucho por descubrir}

Panorama mundial del periodismo de investigación

el trabajo se puede visualizar en la siguiente presentación:

https://prezi.com/iweklc918mbz/mucho-por-descubrirpanorama-mundial-del-periodismo-de-investigacion/ 


\section{Índice}

Un profesión por descubrir [ 11 ]

Prólogo, por Samuel Toledano

Introducción [ 13 ]

1. Américas [ 15 ]

2. Europas [ 67 ]

3. Riesgos y retos [ 91$]$

4. Referencias [ 103 ] 



\section{$\lambda$ \\ Prólogo}

La supuesta crisis que vive el periodismo debe ser matizada constantemente. Las serias dificultades económicas que encuentran los medios de comunicación para dar con un modelo de negocio que ha cambiado profundamente, no tiene que necesariamente extenderse a la crisis en el ejercicio de la profesión. Sin embargo, es conocido que la falta de ingresos, con una marcada caída de la publicidad y las ventas, junto a unos hábitos de consumo que priorizan lo inmediato y lo gratuito, provoca un daño considerable al periodismo de investigación.

La apuesta por una información pausada, con alta dosis de análisis y búsqueda de recursos, así como la necesaria capacidad crítica, hace que el periodismo de investigación se vea como una inversión no tan rentable como otro tipo de información que apunta a la banalidad y el espectáculo como temática y enfoques prioritarios.
Sin embargo, es el periodismo de investigación el que puede cumplir fielmente el derecho fundamental a la información que recogen constituciones, declaraciones de derechos y códigos nacionales e internacionales. Denunciar y ejercer el tradicional concepto del cuarto poder es una garantía de una ciudadanía correctamente informada y formada, preparada para participar en sociedad como un elemento activo.

Una mirada al estado actual se revela como necesaria, al menos para tener un pequeño diagnóstico de lo que sucede $\mathrm{y}$, al mismo tiempo, atisbar algunas de las posibles soluciones para conseguir reforzar su práctica en todo el mundo.

Samuel Toledano 



\section{Introducción}

Elaborar un mapa de la situación mundial del periodismo de investigación es un reto ambicioso. Implica llegar a todos los rincones del planeta y cubrir todas las temáticas. También conlleva acercarse a todos los actores relevantes, desde los profesionales, que trabajan diariamente, a las instituciones públicas y privadas que tienen en su mano regular y garantizar el correcto ejercicio del derecho a la información.

Por eso este libro ha optado por dibujar un panorama, un concepto que se acerca más al esbozo que se ha logrado y que evita las posibles expectativas de un análisis o estudio académico, con todo el rigor que eso implicaría. Aclarar el contenido de este trabajo es, por tanto, una necesidad para garantizar que el lector entienda lo que subyace en él, desde el propósito con el que se inició hasta el resultado final.

La propia metodología del trabajo, así como el contenido final, supone poner en valor la curiosidad el interés de los que han dibujado este trabajo. Los alumnos de la asignatura de periodismo de investigación, como complemento a todos los reportajes realizados durante la asignatura, que son ejercicios reales posteriormente publicados, debían terminar la asignatura al menos con una perspectiva global del contexto en el que ejercen o pueden ejercer su trabajo en España, que distará mucho a la realidad, trágica, de otros lugares. Aunque es cierto, sin embargo, que los patrones de trabajo y los sistemas mediáticos y políticos son prácticamente idénticos.

El panorama realizado aquí es incompleto en lo geográfico, sin presencia alguna de África, Asia y Oceanía. Más completo lo es en su enfoque temático, cubriendo o recogiendo testimonios que abordan cuestiones como los condiciones laborales y profesionales, incluyendo, lamentablemente, las amenazas y muertes de muchos periodistas sólo por hacer su trabajo. 
Este retrato viene a demostrar así la visión que un alumno de periodismo, de Canarias (España), tiene sobre el periodismo de investigación en el mundo. Y que no deja de ser una evidencia de las referencias que tiene, lo que mayoritariamente le llega y que así refleja. Estados Unidos queda retratado como un posible origen del periodismo de investigación, y con algunos de sus casos más llamativos, algunos de ellos llevados al cine. Y junto a este país, el resto de América, con un protagonismo evidente del mundo en español, que luego se extiende al retrato de Europa, que se limita prácticamente a España.

El idioma se convierte así en un elemento vital, que posibilita conocer otras propuestas que están muy alejadas geográficamente. Pero al mismo tiempo supone una clara limitación, que impide conocer lo que sucede en otras partes del planeta por no dominar otros idiomas. Una ausencia que también debe ser comprendida dado los referentes culturales y educativos que llega al alumnado.

El trabajo retrata el protagonismo del periodista de renombre. El periodismo de investigación se vincula así a profesionales reconocidos, buscando a esos nombres que marcan tendencia y que se posicionan públicamente, muchos de ellos en televisión. Esto supone un elemento positivo, al evidenciar que esta labor adquiere notoriedad, pero supone un reverso muy negativo, pues la personificación de los reportajes puede quitar el protagonismo a las historias. Los medios, aquí, quedan prácticamente ausentes. Es el peso de la persona (la cara y el nombre), y no el medio y su supuesto trabajo en equipo, lo que más preocupa de esta visión. Este personalismo esconde, por otro lado, un elemento interesante, y es la presencia de mujeres. Aquí hay muchas profesionales que lideran su trabajo en América Latina. Una presencia a destacar que, en el caso de España, tiene el reverso negativo, puesto que es del todo inexistente.

Hay que remarcar, nuevamente, que el trabajo aquí expuesto no es completo ni tampoco ha buscado el equilibrio temático o geográfico, salvo la pauta inicial de que fuese un panorama mundial. Existen obviamente muchos profesionales, hombres y mujeres, así como muchas temáticas y muchos países, que no salen reflejados, al igual que muchos medios convencionales o alternativos que desarrollan una gran labor. El interés aquí está en asumir, como punto de partida, que este trabajo es el reflejo de lo que ve, escucha y conoce un alumno que está finalizando la carrera de periodismo. Es un excelente punto de partida sobre el cual se debe construir no sólo el periodismo de investigación sino también la trascendencia que esta labor debe tener para el conjunto de la sociedad. 



\section{Muckrakers}

"Los muckrakers -literalmente husmeadores de basura o rastrilladores de estiércol- son figuras míticas del periodismo profesional nacidas a finales del siglo XIX y principios del siglo XX. Su denominación fue acuñada por el presidente de Estados Unidos Theodore Roosevelt, en un discurso público pronunciado el 14 de abril de 1906, en el que se refería a un tipo especial de periodistas que 'sólo sabían hurgar en lo negativo de los personas para denunciar y escandalizar a la sociedad', sobre todo cuando se trataba de funcionarios públicos" (1). 



\section{Características del fenómeno muckraking:}

1. Espíritu de denuncia de corrupciones escandalosas y énfasis en los abusos de autoridad.

2. Atención prioritaria a los desórdenes morales, tomada de la tradición popular sobre crímenes y sucesos.

3. Utilización de caricaturas como Thomas Nast, creadores de imágenes impactantes.

4. Empleo de un tono estridente en los artículos de opinión, heredado de los panfletistas de la guerra civil norteamericana.

5. Combinación de noticias documentad las sobre casos individuales de abusos, con campañas sistemáticas a favor de determinadas reformas.

6. Un sentido indiscriminado de la búsqueda de escándalos de corrupción husmeando en todas las direcciones: desde hombres de negocios apolíticos, falsos líderes religiosos e incluso periodistas de la competencia. (2) 



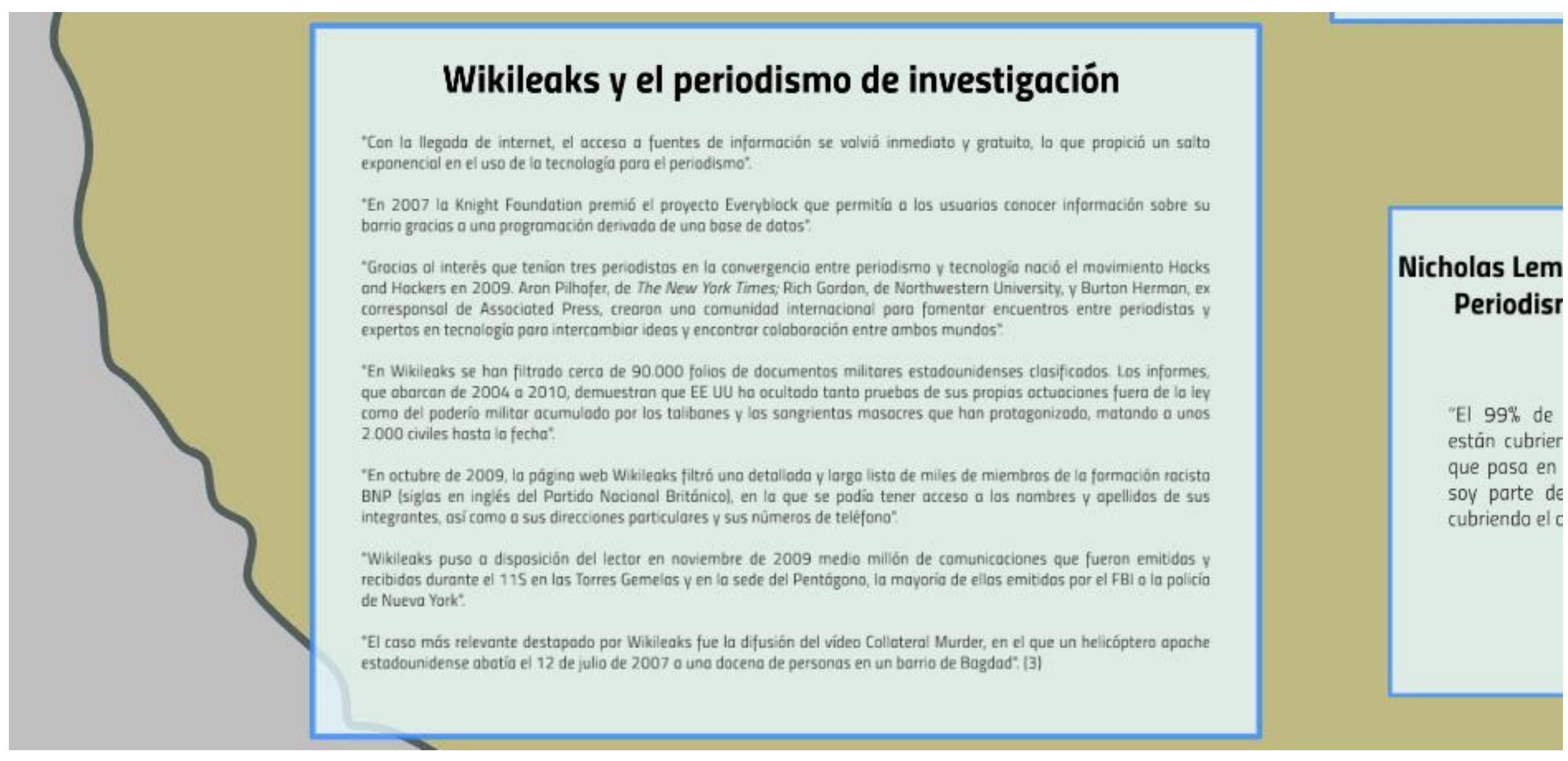





\section{:mérito de la Facultad de rsidad de Columbia) \\ Spotlight}

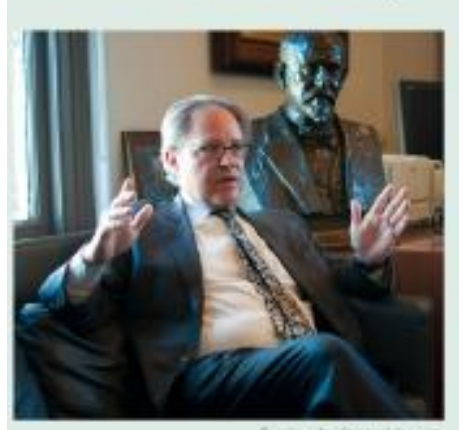

En 2002 un equipo de periodistas del equipo de investigaciôn de The Boston Globe llamado Spotlight llevo a cabo una investigación sobre unos posibles casos de pederastia en Masachussets.

Este grupo de periodistas de The Boston Globe publicaron tras un año de investigación que el sacerdote Geoghan había abusado de por lo menos 130 niños entre 1960 y 1998

Las pesquisas llevaron a concluir que alrededor del $10 \%$ del clero de Boston había abusado, de uno u otro modo, de menores, con el conocimiento y consentimiento del cardenal Law, quien poco después de la investigación tuvo que dimitir. Varios años después huyó al Vaticano para escapar de un juicio que hubiera acabado con él entre barrotes. crpptocat una senc
internet o part teléfon

Teletenes viglioncia, incluso appogados

Medios fisicos. Cubcise can una toalla mientros se tediea una tu

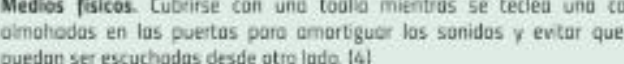





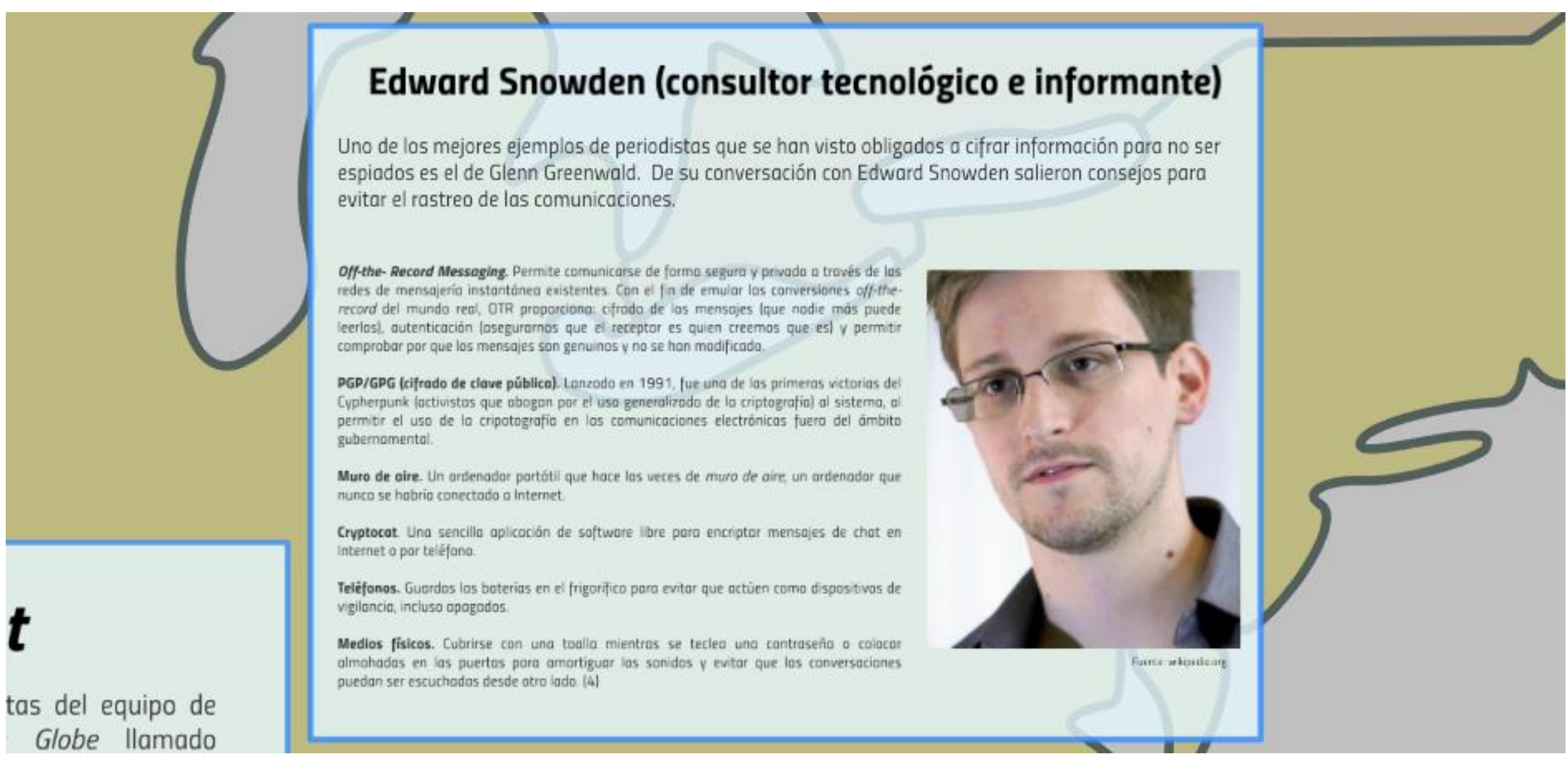





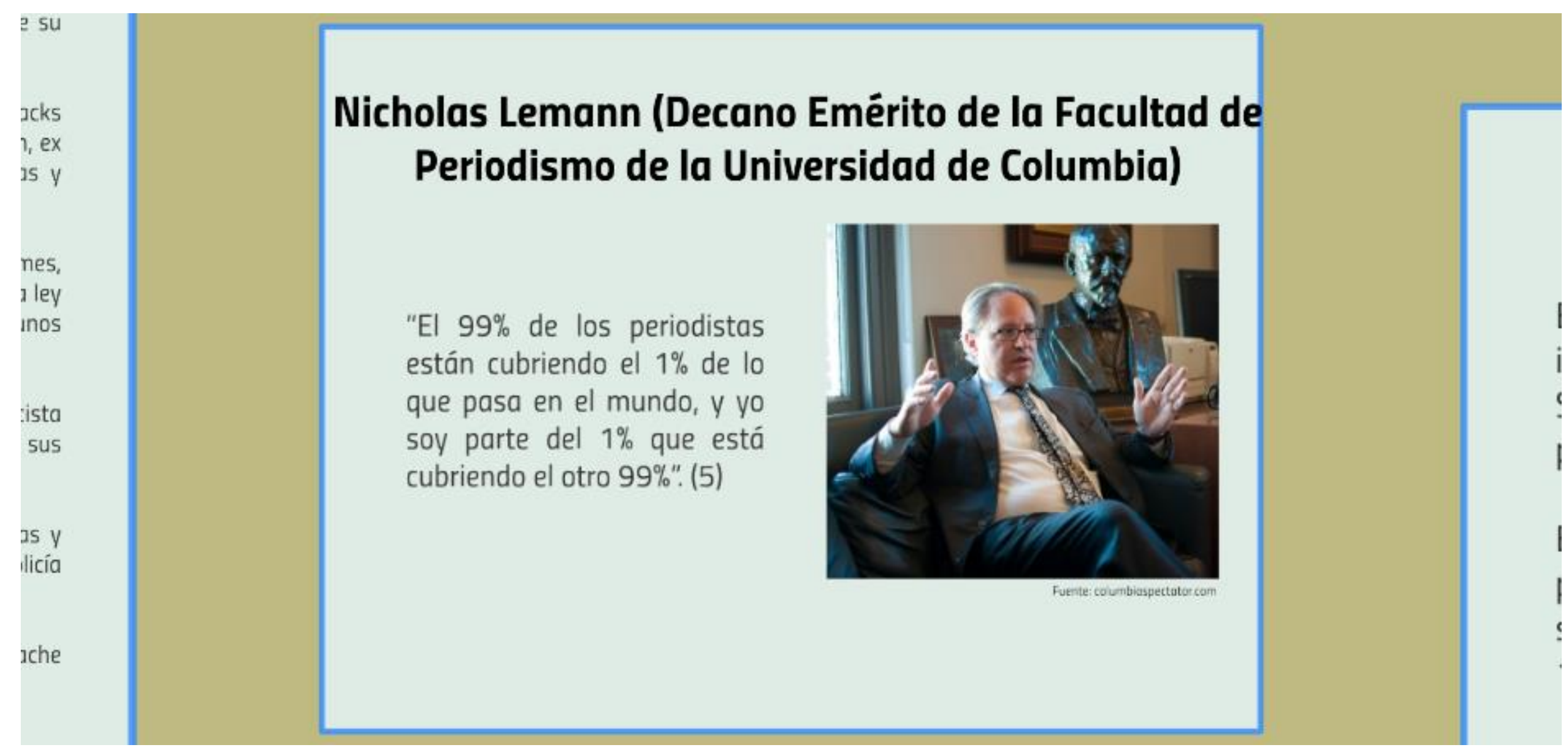





\section{Legislación en México}

La Ley para la Protección de Personas Defensoras de Derechos Humanos y Periodistas fue aprobada en México, el 25 de junio de 2012, con el objetivo de proteger jurídicamente a los defensores de los Derechos Humanos y a los profesionales de la comunicación. 



\section{Paola Rojas Hinojosa (periodista de Televisa)}

"Me queda claro que el periodismo de investigación vinculado al narcotráfico ya no se puede hacer en nuestro pais. Hay ámbitos del periodismo que han quedado fuera del alcance de todos justamente por la amenaza que representa el crimen organizado.

Eso es lo que hace peligroso ejercer el periodismo en México. Sí me parece que en términos de amenaza por parte del gobierno, hay lugares muy focalizados en donde sí hay gobernadores que siguen queriendo ejercer esta represión y siguen queriendo callar bocas, pero en realidad eso ya no se puede hacer, yo

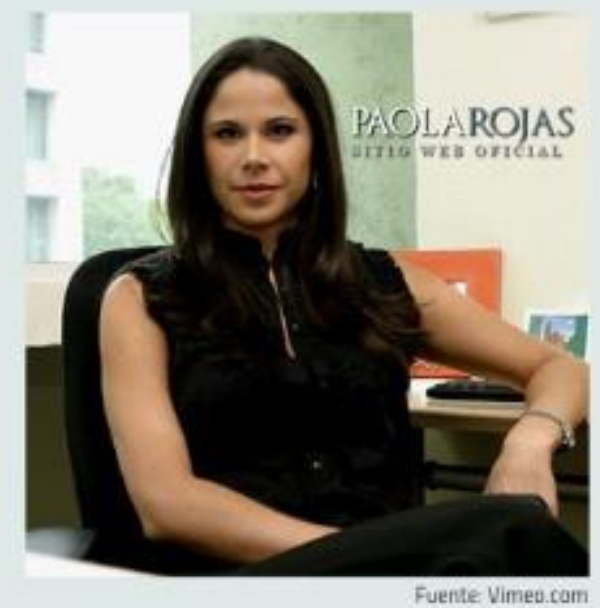

no se puede tapar el Sol con un dedo.

Ya hay mecanismos, redes sociales, hay

instrumentos tecnológicos que hacen que la

información no se pueda ocultar". (6) 



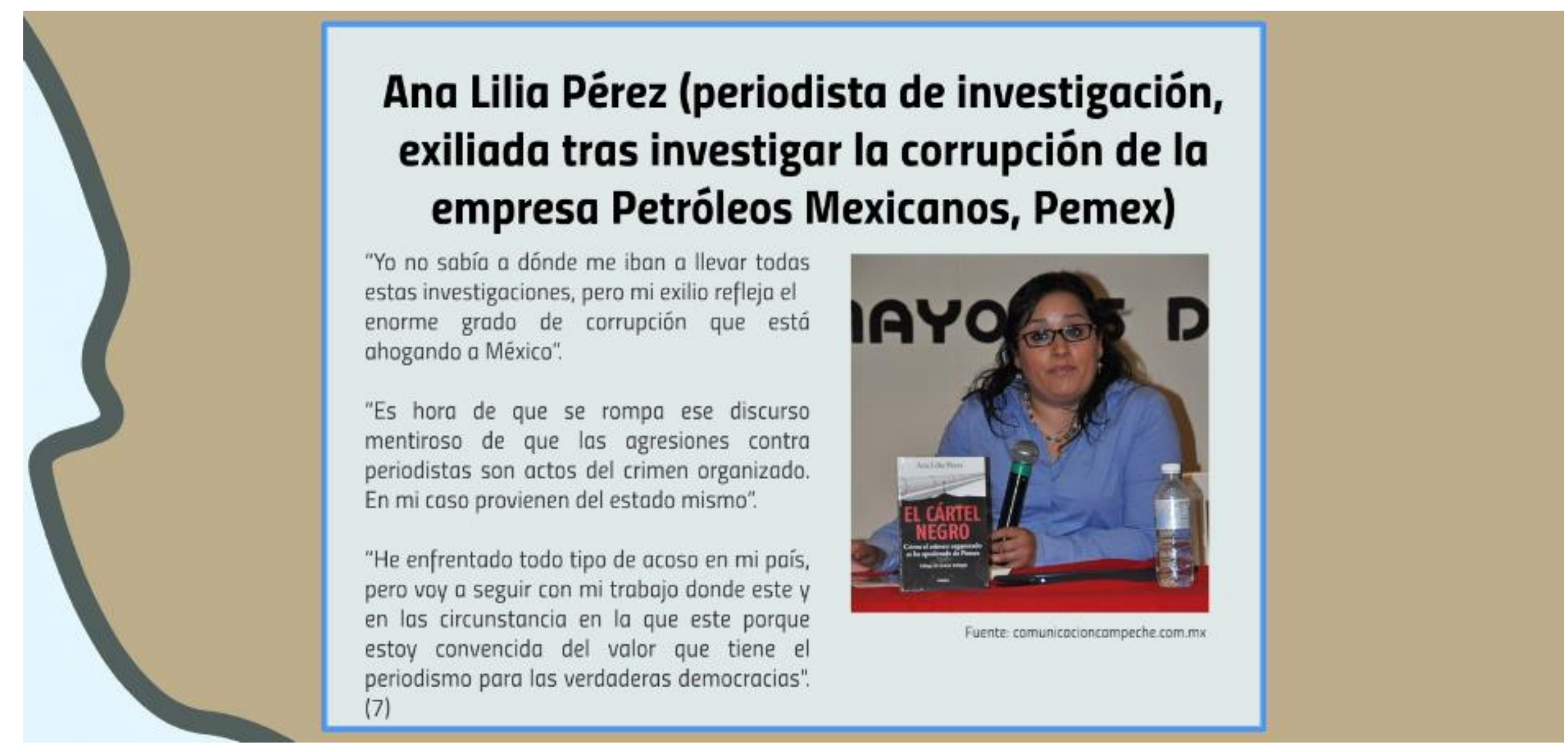



INFORME estadístico de la Fiscalía Especial para la
Atención de Delitos Cometidos contra la Libertad de

Expresión de la Procuraduría General de la República:

México es uno de los países más peligrosos para ejercer el Periodismo. En este país, nueve de cada diez delitos quedan impunes.

En los últimos 15 años, fueron asesinados en México

103 periodistas y desaparecieron 25

En 2010 crearon una Fiscalía para Delitos contra la Libertad de Expresión

Dentro de América Latina, uno de cada tres asesinatos de reporteros se comete en México.

Ocupa el lugar 148 de 180 países en la Clasificación

Mundial de la Libertad de Prens

En 2014 fue el país más mortífero para los informadores (según Reporteros Sin Fronteras)

En 2015 fueron asesinados 14 periodistas (según la

FPL, Federación de Periodistas Latinoamericanos)

Cada 22 horas un periodista es agredido en México

(según la Organización Internacional Art.19) 



\section{Periodismo de Investigación en El Salvador}

El periódico salvadoreño El Faro reveló el 14 de marzo de 2012 que el gobierno de El Salvador había negociado con las pandillas una disminución de homicidios a cambio de beneficios penitenciarios.

Documentó el acuerdo secreto del gobierno con los líderes de las pandillas para reducir la violencia en ese país a cambio del traslado de una treintena de cabecillas pandilleros internados en cárceles de máxima seguridad a cárceles de menor régimen de custodia, a pesar del amplio historial delictivo de estos. 



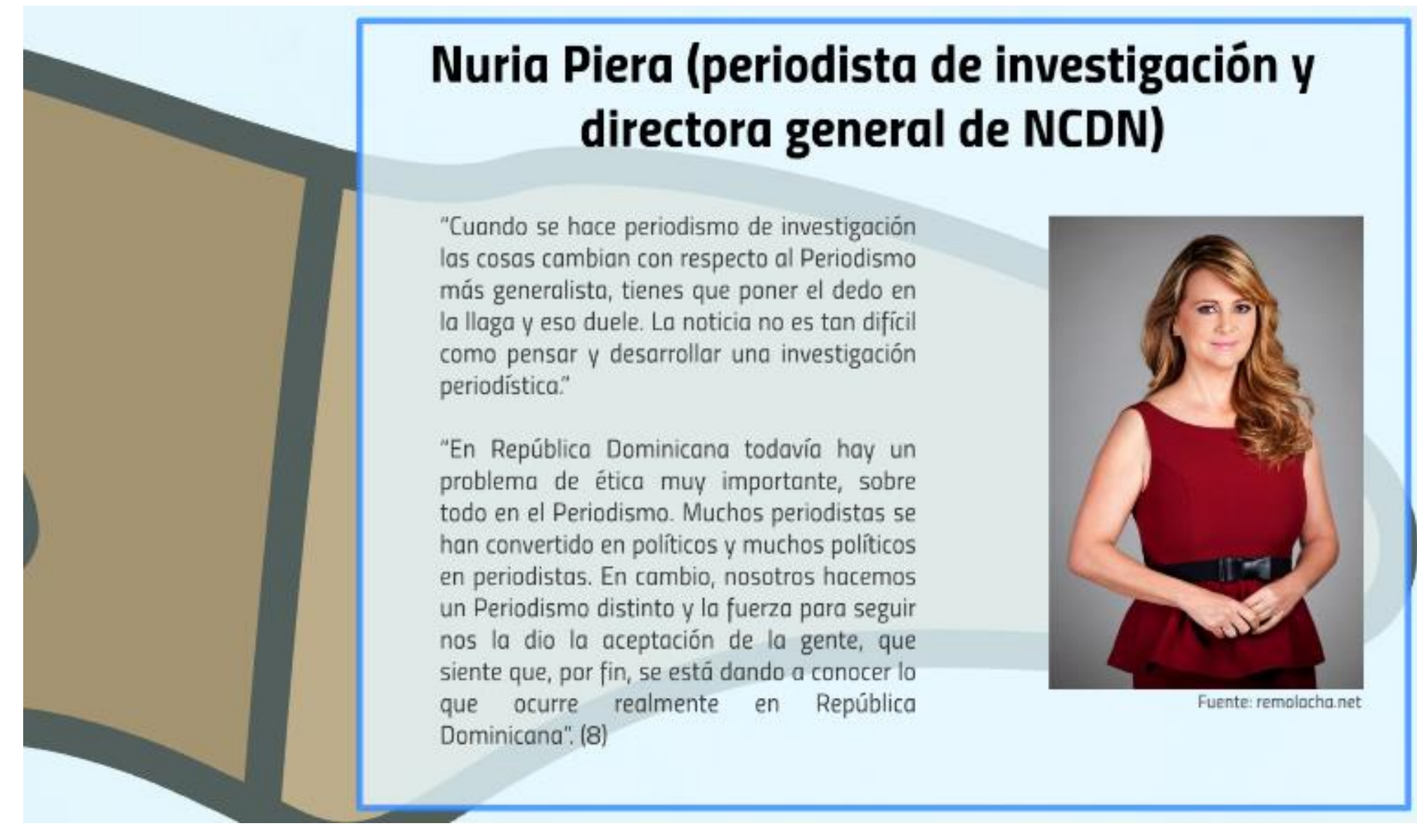





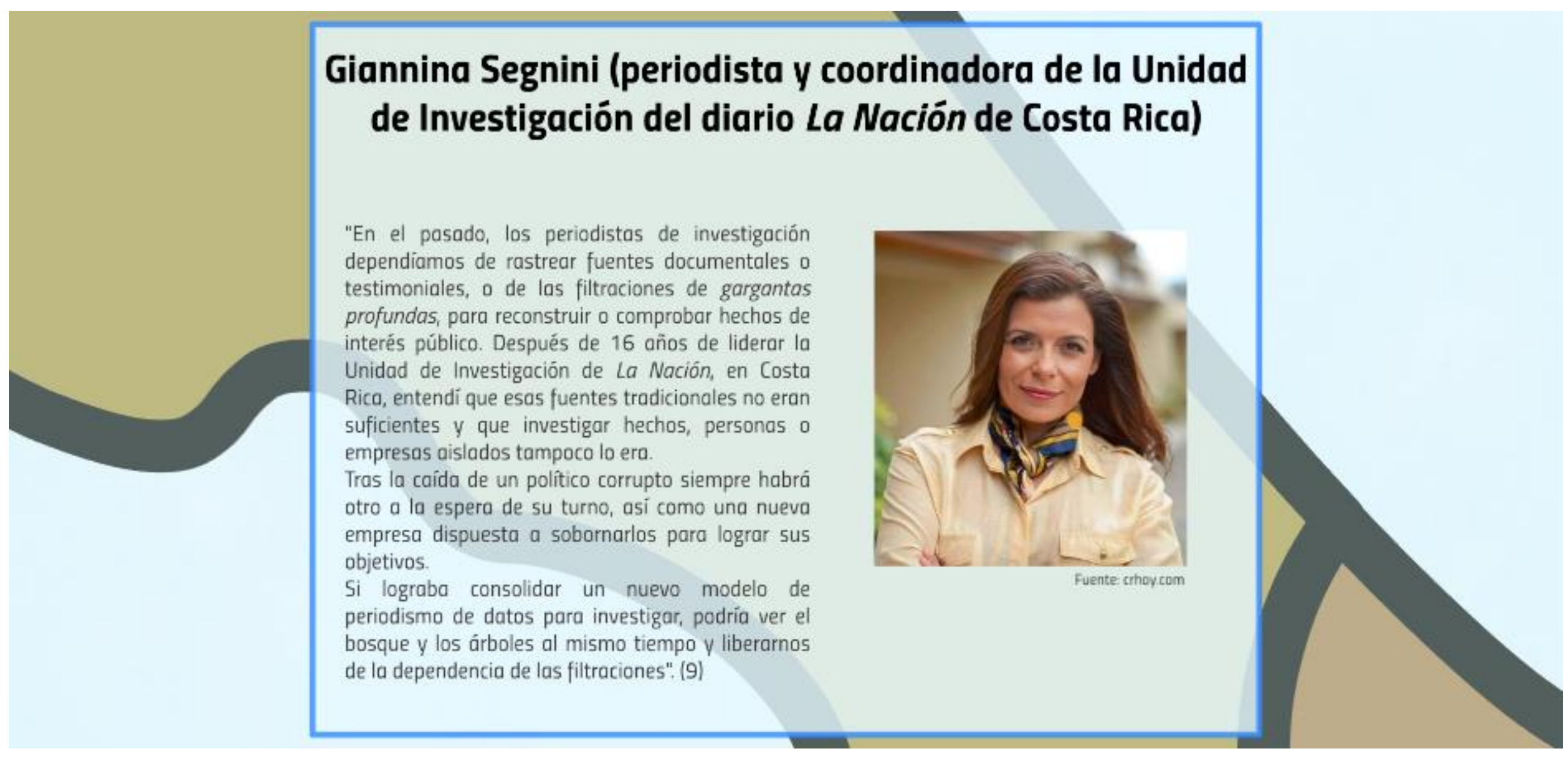





\section{Código de ética del periodista venezolano}

Articulo 42. El periodista tiene el deber insoslayable de defender la Soberanía Nacional y la integridad territorial. En consecuencia, debe contribuir con su acción gremial en esta patriótica tarea, oponiéndose a toda prédica o campaña que contrarie el interés nacional, así como la paz y la amistad entre los pueblos.

Artículo 43.El periodista debe exigir del Estado la aprobación de una legislación que lo proteja contra los efectos del monopolio u oligopolio de los medios de comunicación social.

Articulo 44. El periodista debe rechazar presiones que puedan ejercer gobiernos y grupos económicos, políticos o de cualquier otra índole para deformar, manipular o censurar informaciones.

Articulo 45. El periodista tiene el deber de combatir sin tregua a todo régimen que adultere 0 viole los principios de la democracia, la libertad, la igualdad y la justicia. Articulo 46. El periodista que trabaje en sector público debe rechazar las presiones que pueda ejercer el Estado, en el sentido de lograr una identidad ideológica. Artículo 47. El periodista y los órganos regulares del Colegio serán los únicos responsables de asegurar la observancia y vigilancia de estos principios éticos. En consecuencia, nada puede justificar la intervención de cumplimiento o sanción a quienes violen el presente Código. 



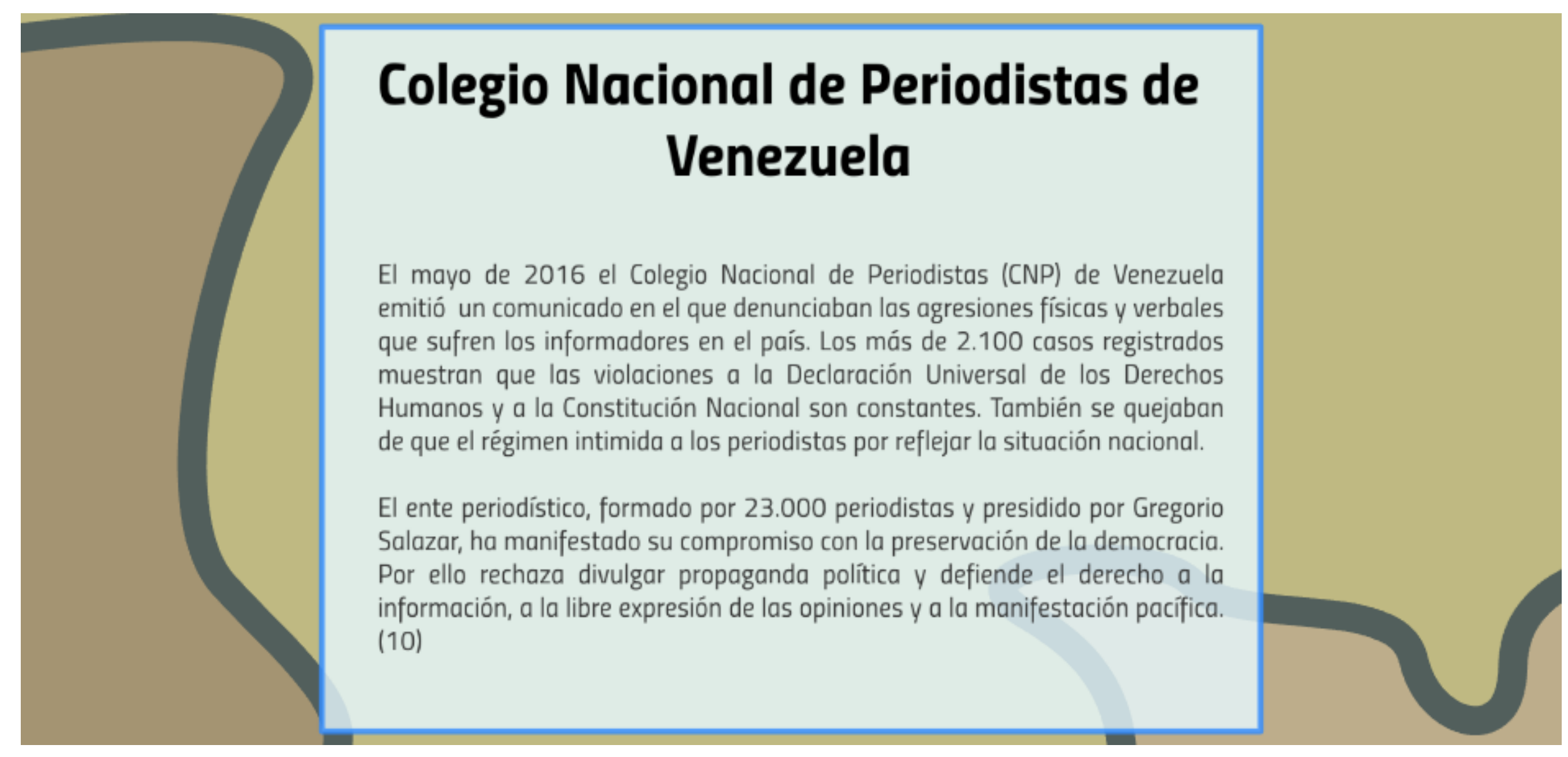





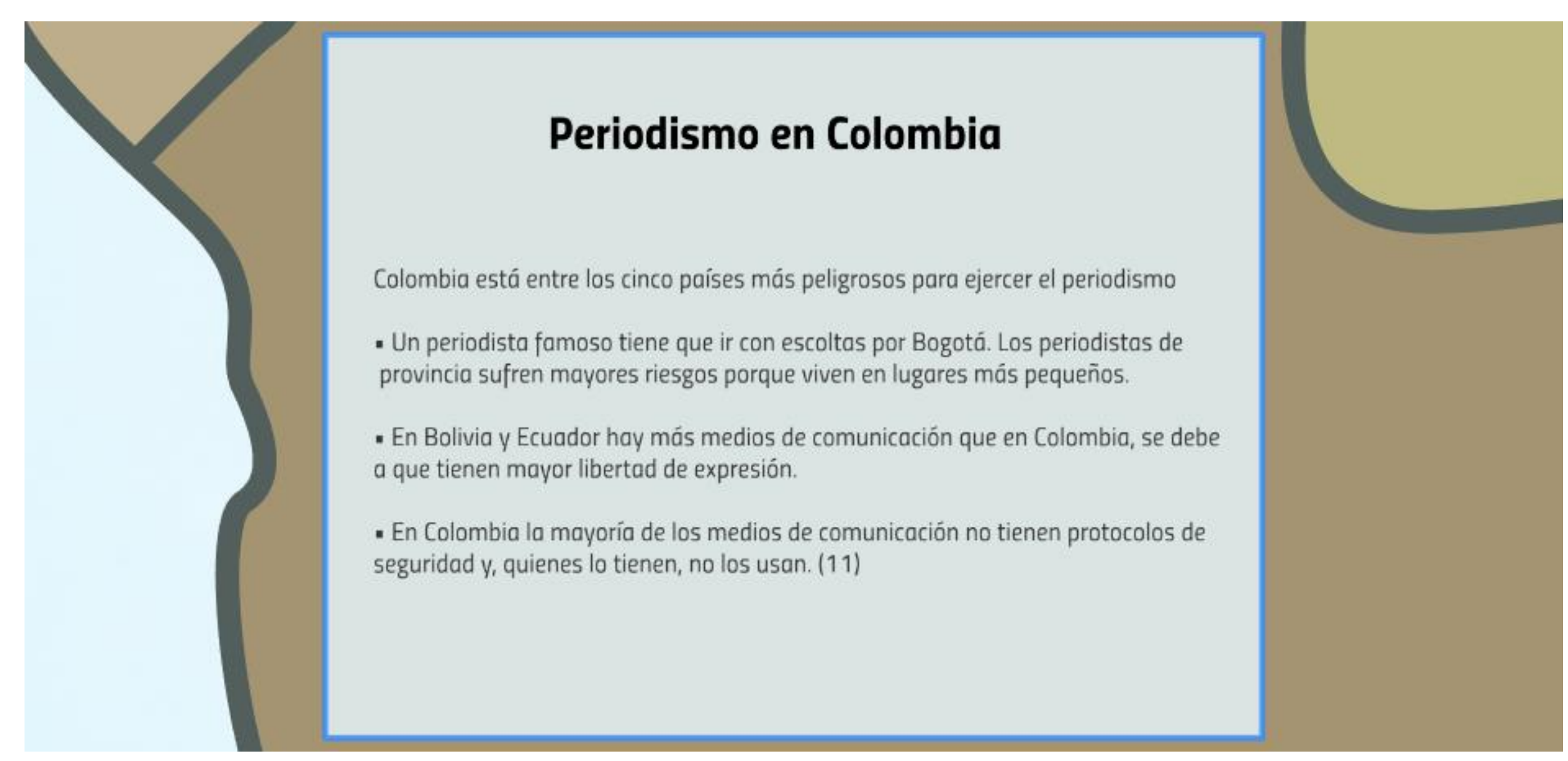





\section{Juanita León (periodista y directora de La Silla Vacía)}

"Cada vez que los medios tradicionales se meten en una investigación, el impacto que tienen es impresionante [...].Pero como está cambiando tanto el modelo de negocio, muchos - asustados con razón porque internet ha destruido las bases de ese negocio- han seguido el camino que siguieron revistas como Newsweek de ampliar las audiencias y de irse por temas más livianos. Creo que ahi puede estar la semilla de la destrucción. Entiendo el dilema en el que están y el mundo entero está en eso. Pero, en cambio de hacer cosas más light, haría investigaciones más profundas porque eso es lo que no pueden hacer los ciudadanos". (12)

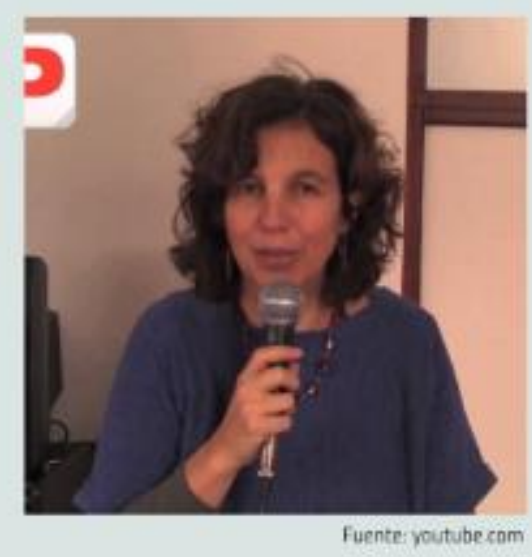





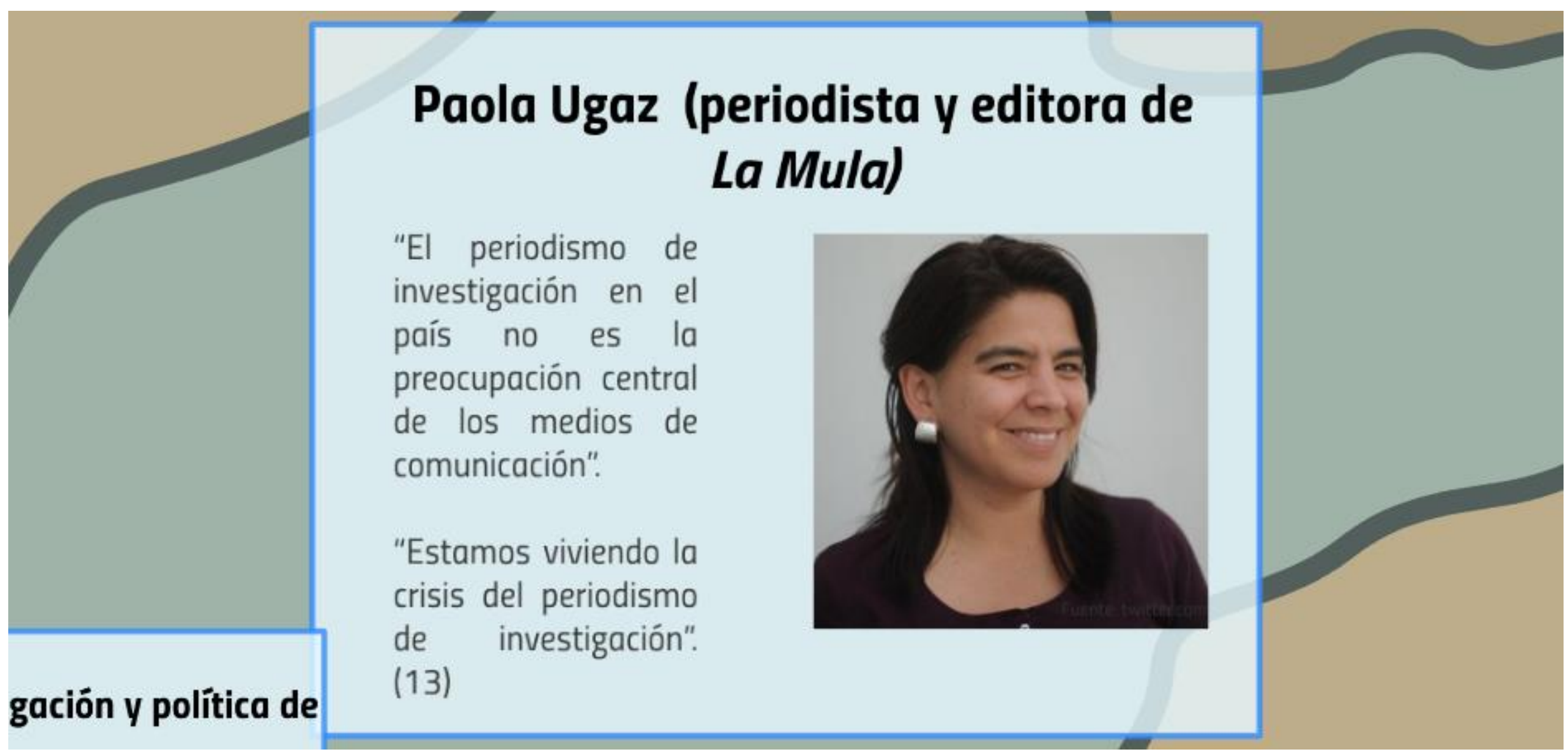





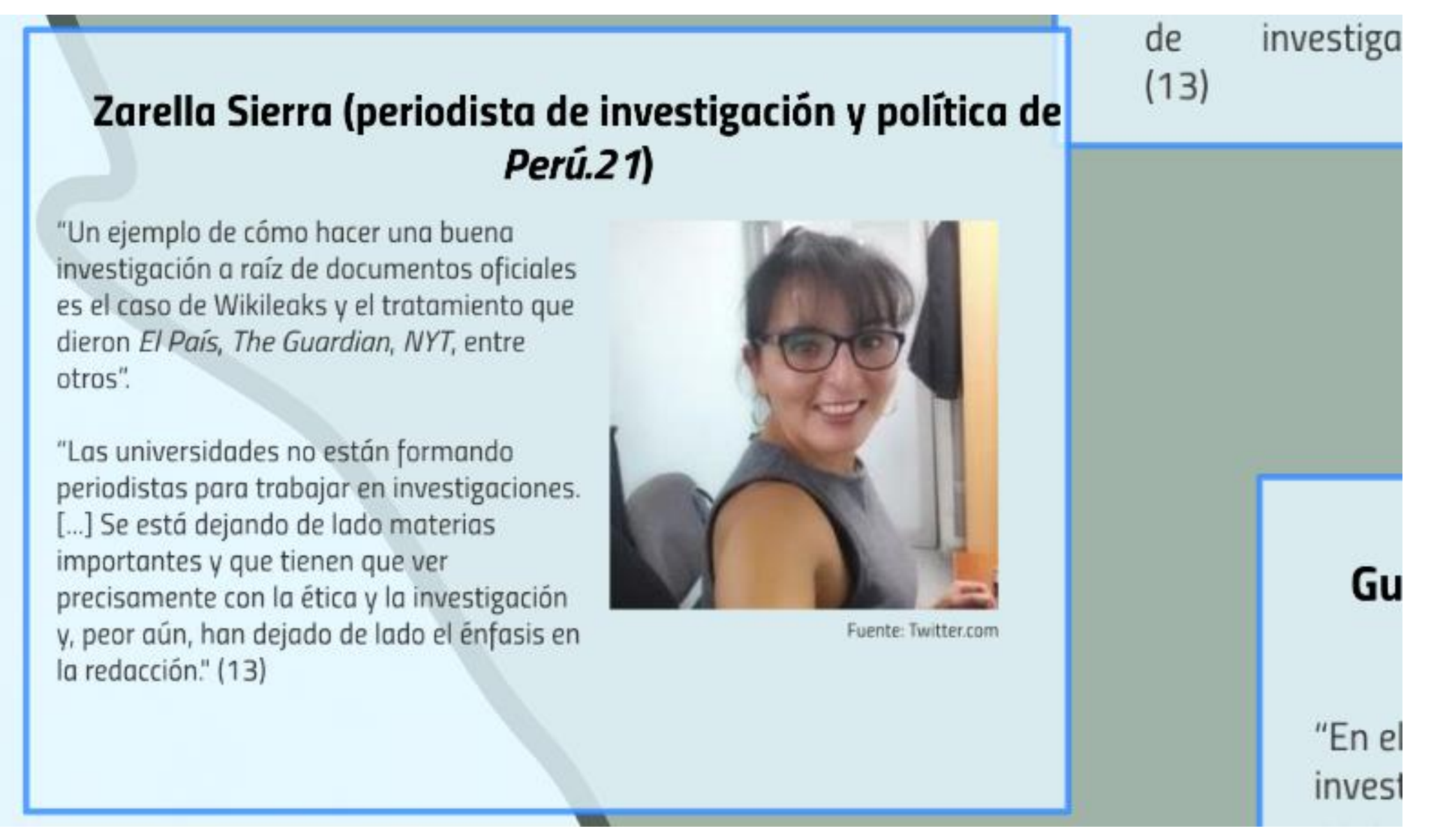





\section{Gustavo Gorriti (periodista de investigación)}

"En el Perú no se hace investigación periodística porque es costosa y trae consecuencias".

"El periodismo de investigación en el Perú esta extinguido". (14)

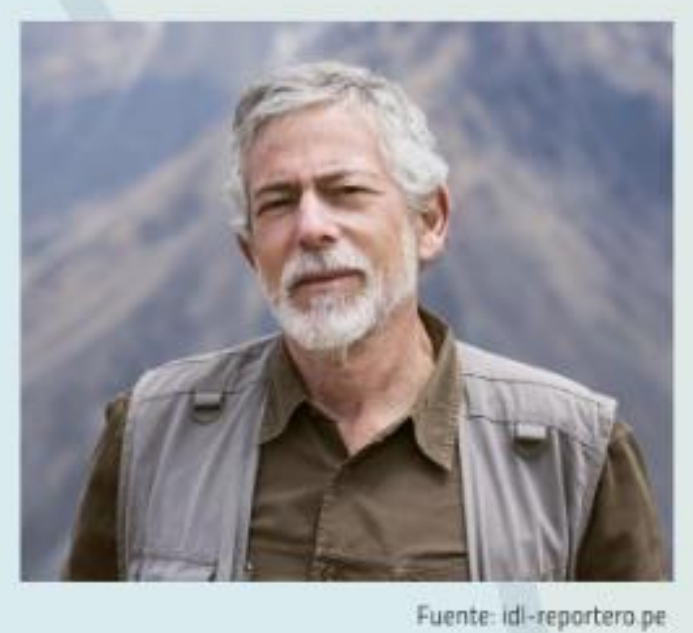





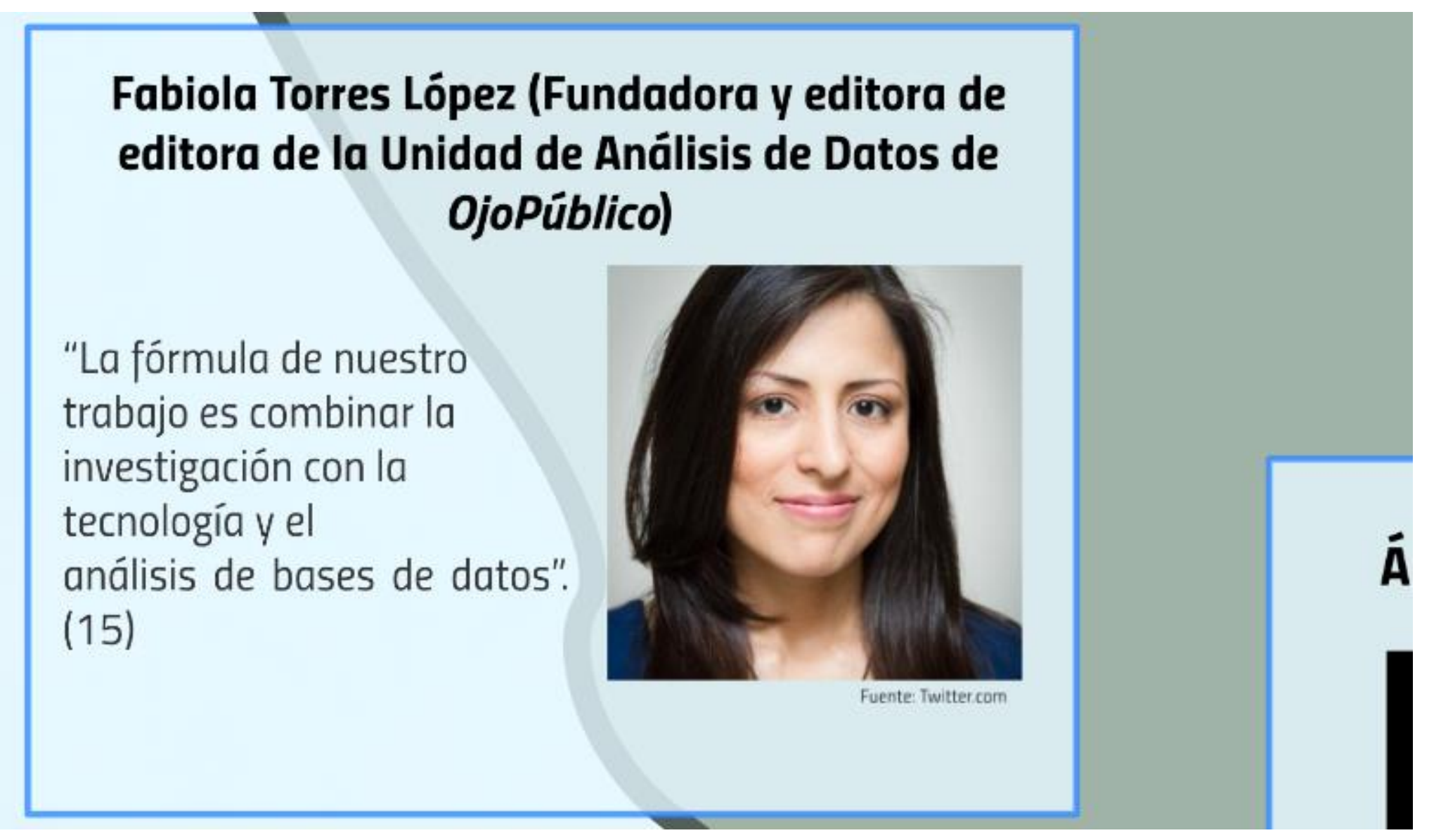





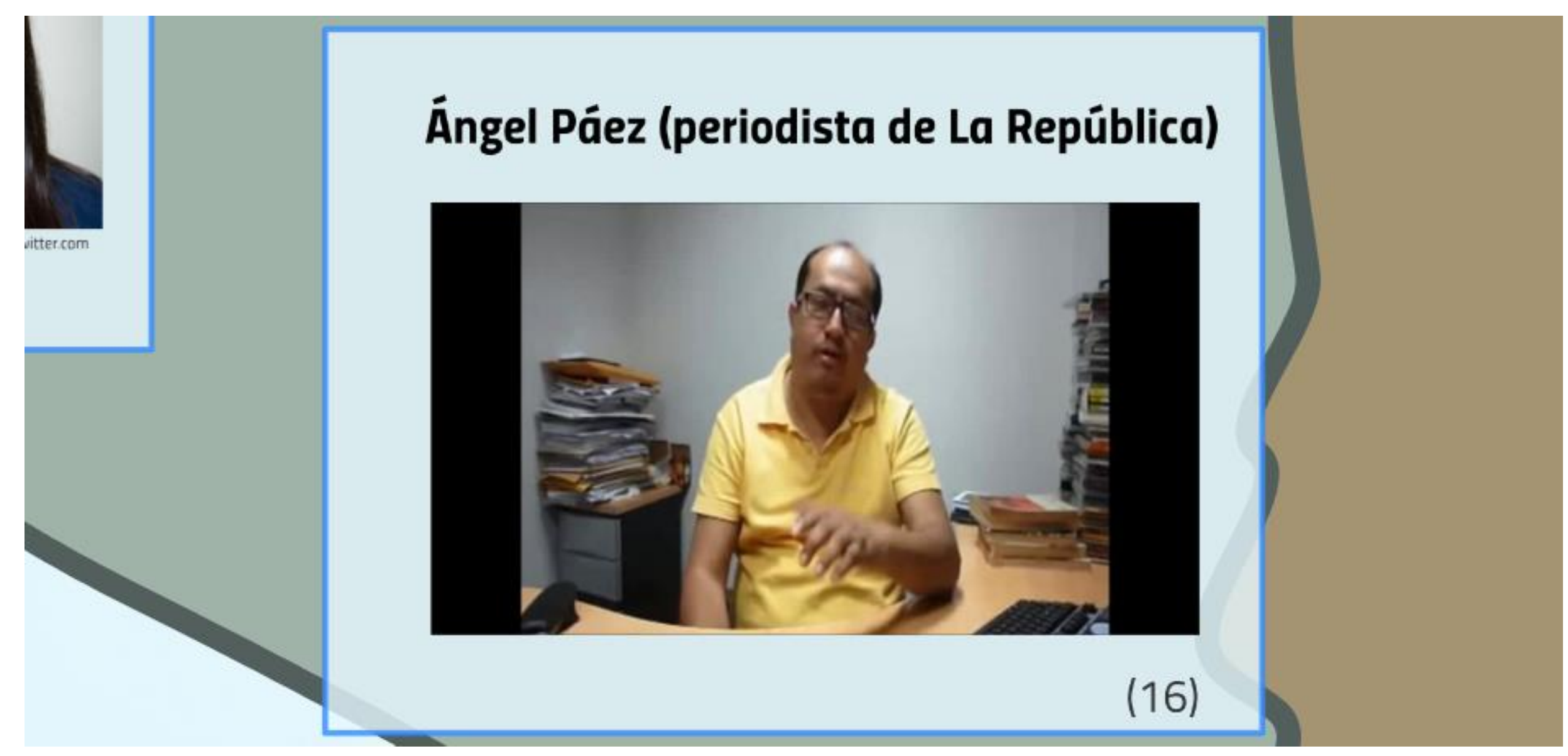





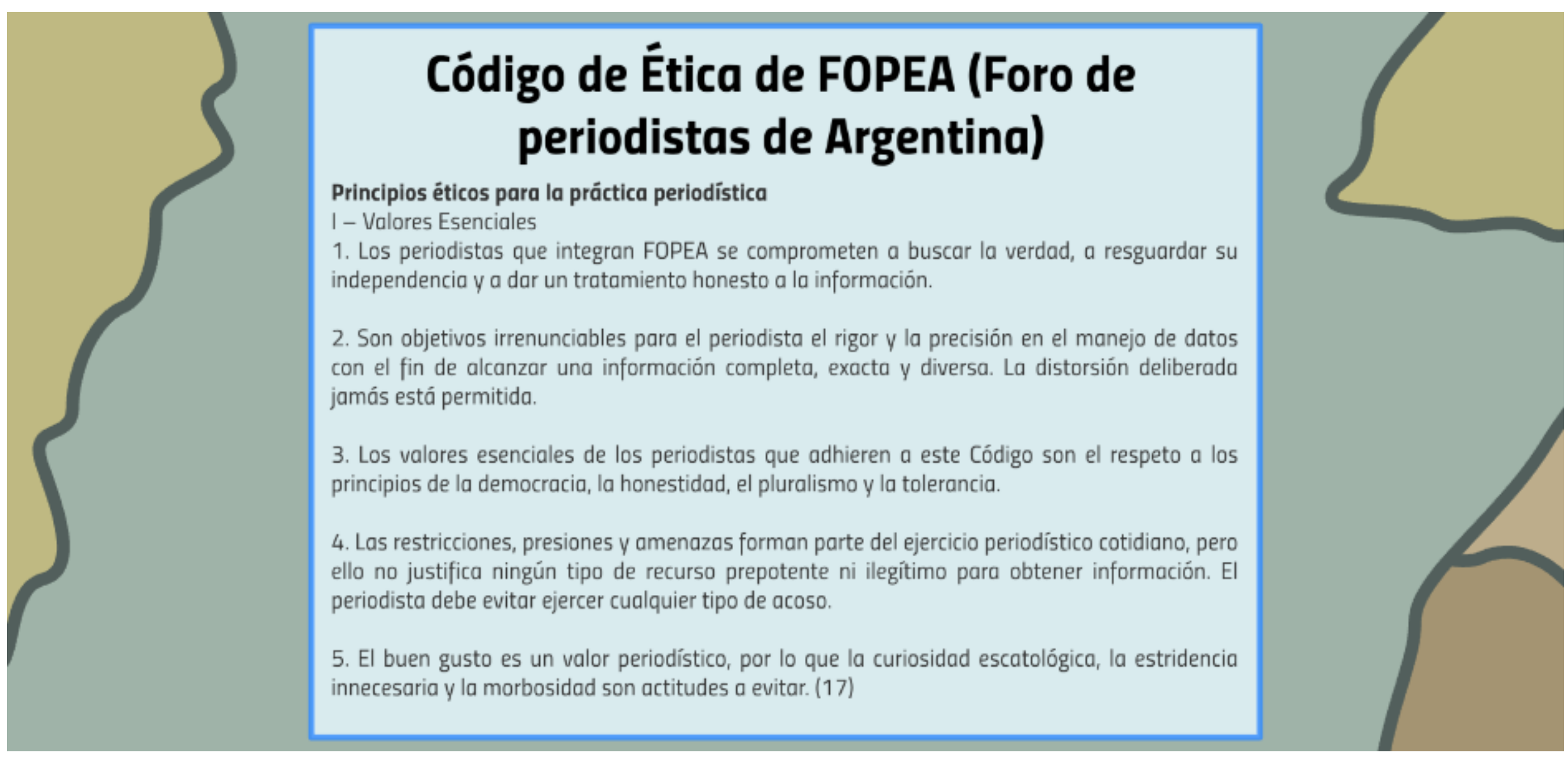





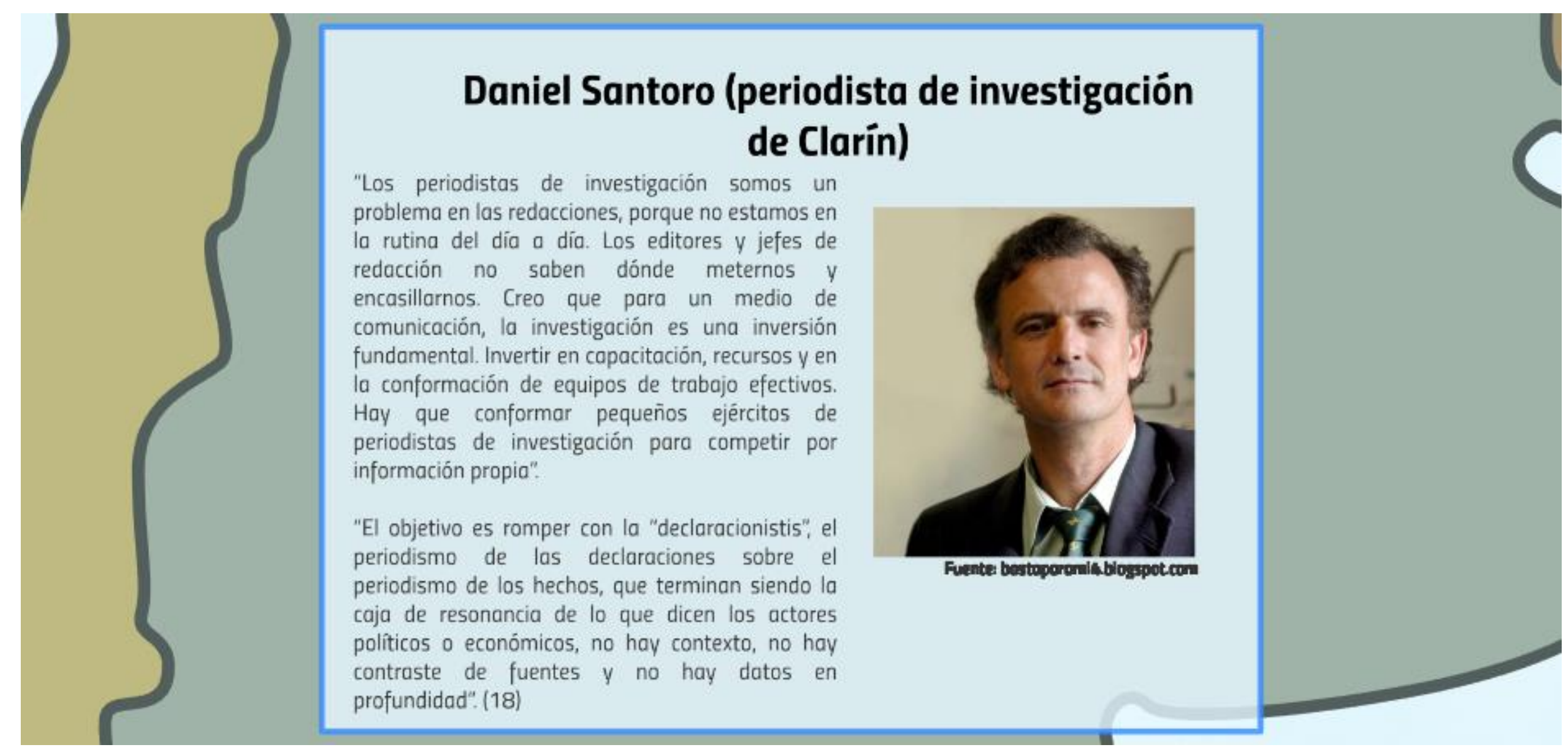





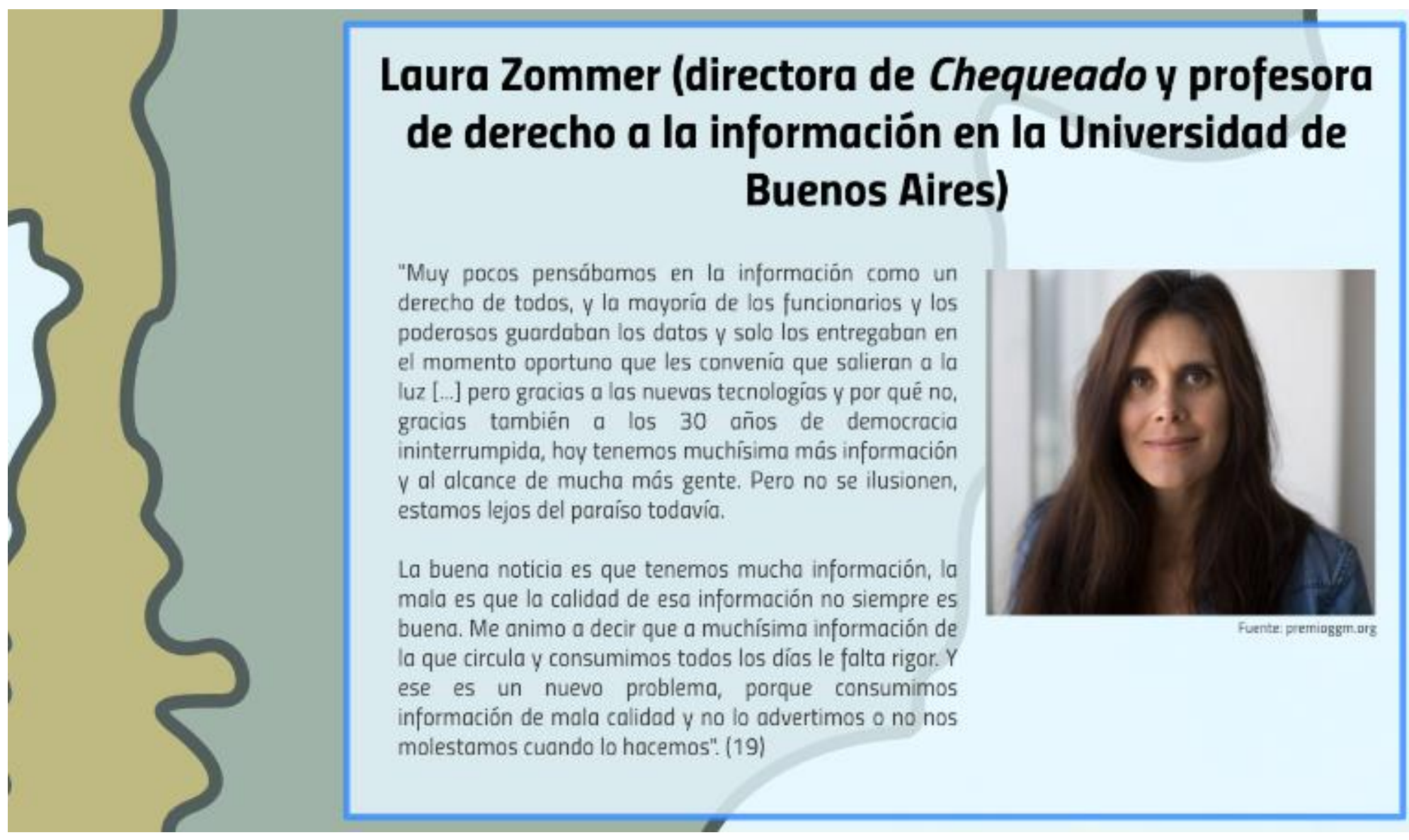





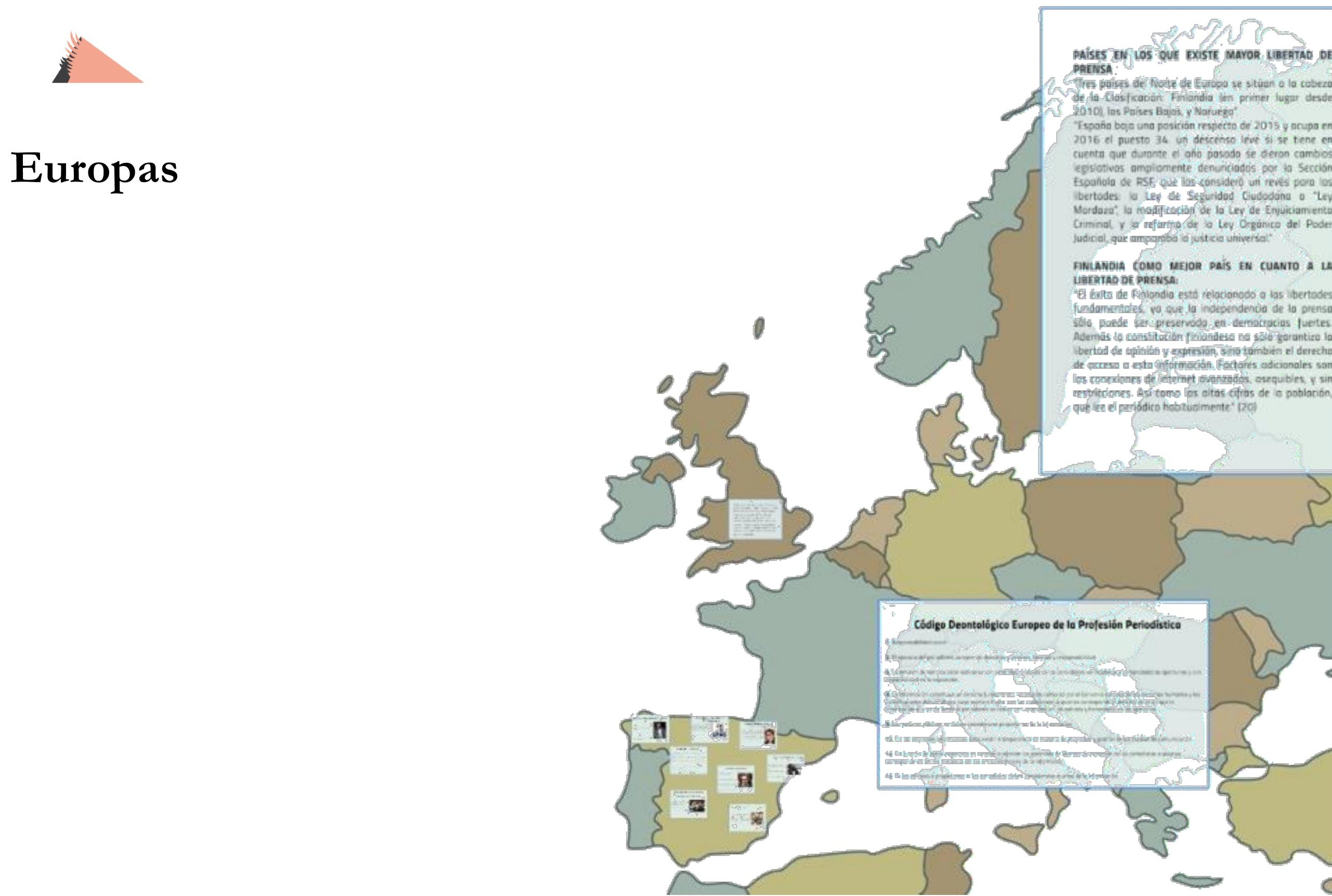



En Europa, el periodismo de investigación puede datarse en 1885, cuando, a la edad de 35 años, un periodista protestante y religioso convencido, William Stead, embarcado en una especie de cruzada contra la prostitución infantil, denunció cómo en el Londres victoriano se podían comprar los servicios sexuales de jóvenes prostitutas al amparo de las meretrices que las custodiaban. 



\section{Código Deontológico Europeo de la Profesión Periodística}

1. Responsabilidad social.

2. El ejercicio del periodismo comprende derechos y deberes, libertad y responsabilidad

4. La emisión de noticias debe realizarse con veracidad, a través de las actividades verificadoras y comprobadoras oportunas y con imparcialidad en la exposición.

8. La información constituye un derecho fundamental reconocido como tal por el Convenio europeo de los derechos humanos y las Constituciones democráticas, cuyo sujeto o titular son los ciudadanos, a quienes corresponde el derecho de exigir que la

información que se da desde el periodismo se realice con veracidad en las noticias y honestidad en las opiniones.

9. Los poderes públicos no deben considerarse propietarios de la informaciôn.

12. En las empresas informativas debe existir transparencia en materia de propiedad y gestión de los medios de comunicación.

14. En función de estas exigencias es necesario reforzar las garantías de libertad de expresión de los periodistas a quienes

corresponde en última instancia ser los emisores finales de la información.

15. Ni los editores o propietarios ni los periodistas deben considerarse dueños de la información.

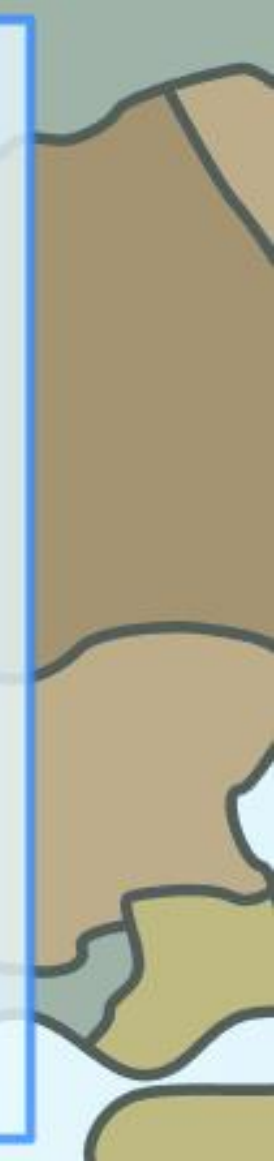





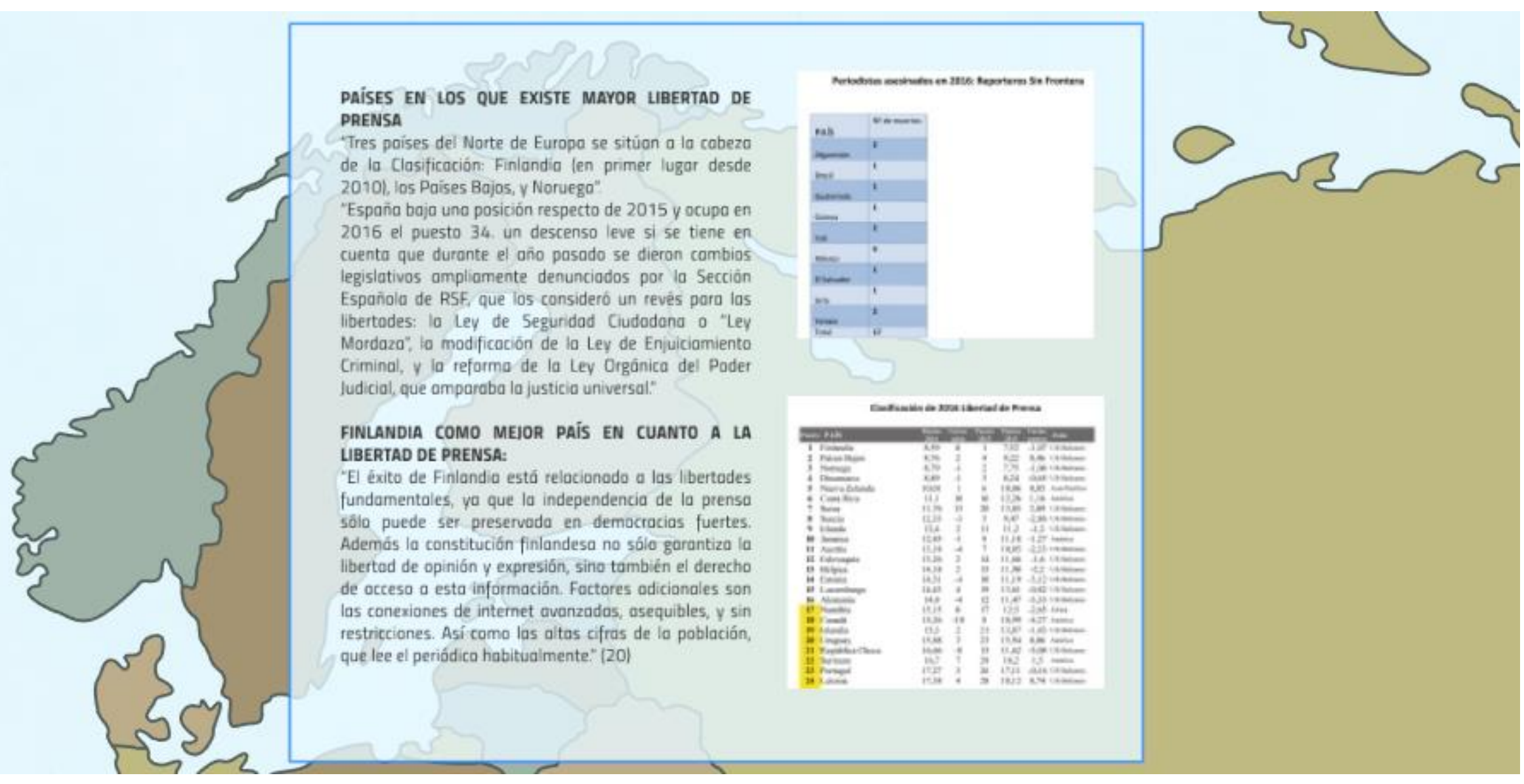





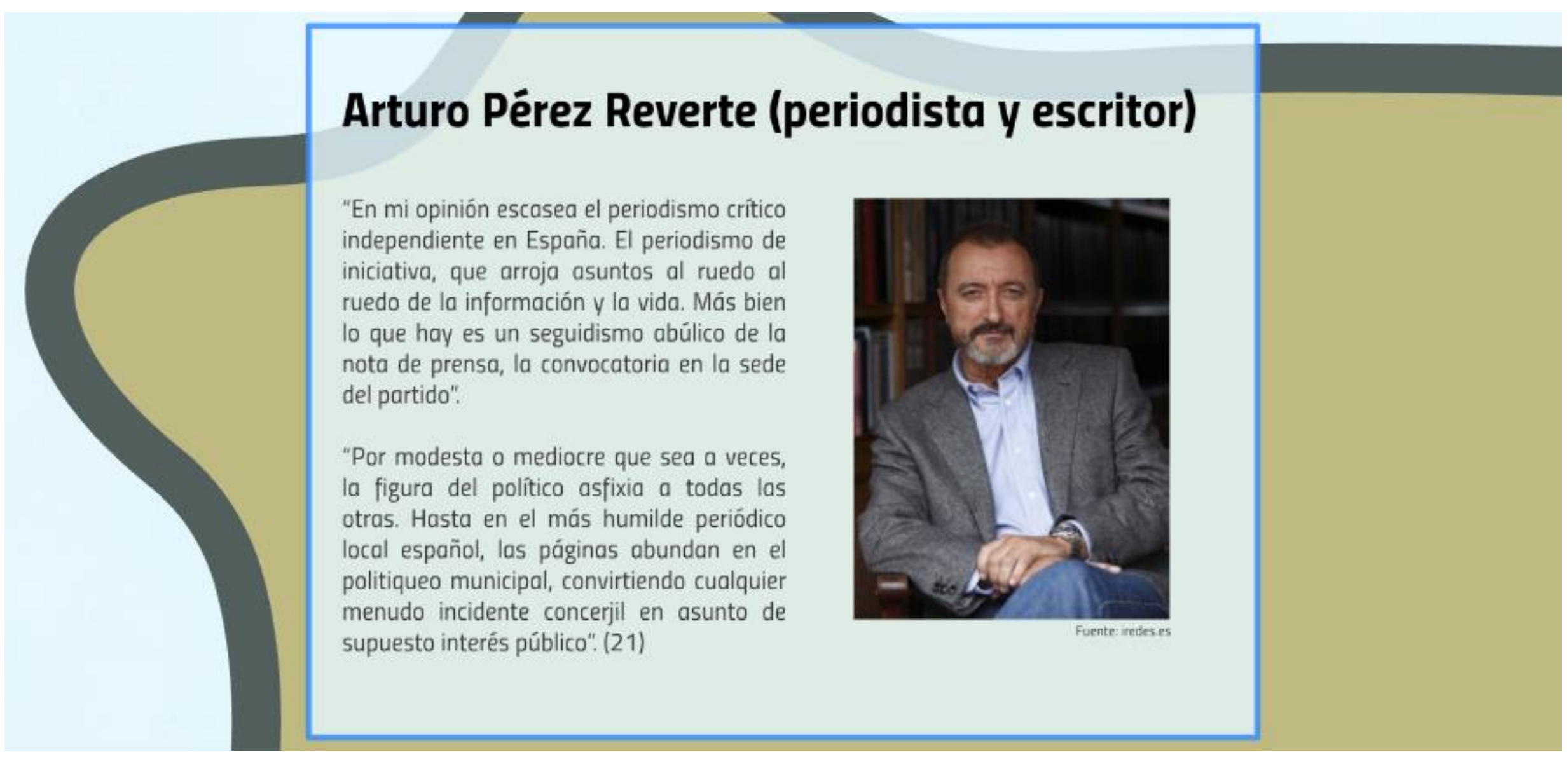





\section{Nacho Cardero (periodista de El Confidencial)}

"Un periodista es una persona cualificada que sabe jerarquizar la información; sabe discernir lo que es importante de lo que no y aplica a su trabajo tres cualidades muy importantes: el rigor, la solvencia y, sobre todo, la responsabilidad en el trabajo que hace."

"En un mundo en el que abundan los intereses y dependencias económicas [...] donde el periodismo de investigación resulta caro y poco rentable, [...] la cooperación entre medios irrumpe como clave del periodismo futuro". (22)

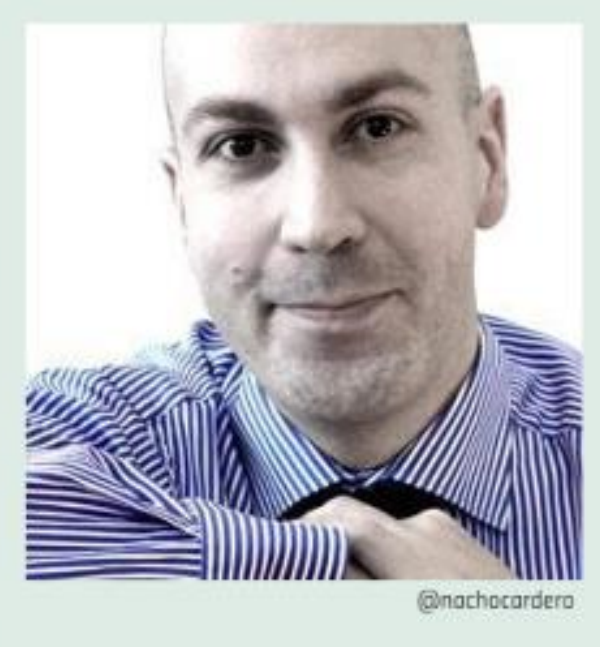





\section{Montserrat Quesada (profesora de periodismo de investigación)}

"En todo el Estado y desde 1978 he llegado a contabilizar más de 2.000 reportajes de investigación que no han podido ser rebatidos por las personas que en ellos se denunciaban".

"Las sociedades modernas y los tiempos actuales exigen que la libertad de información y la crítica pública del poder no se construyan solamente a partir de simples opiniones de los más atrevidos. Es necesario que tales opiniones vayan respaldadas por la solidez de los hechos y para ello el trabajo de investigación es tarea ineludible". (23)

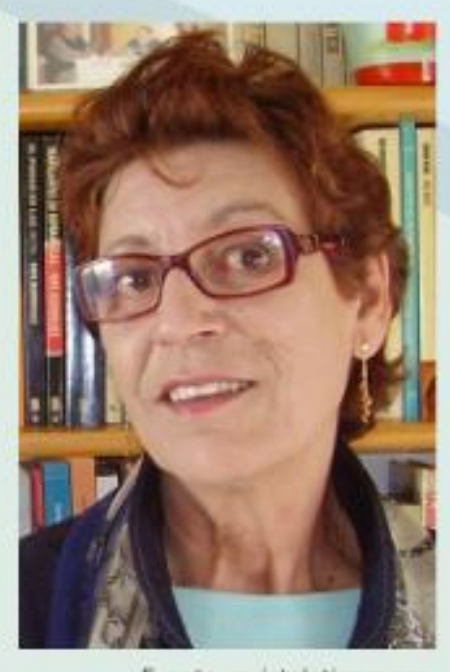

Fuente revistalatinacs org 



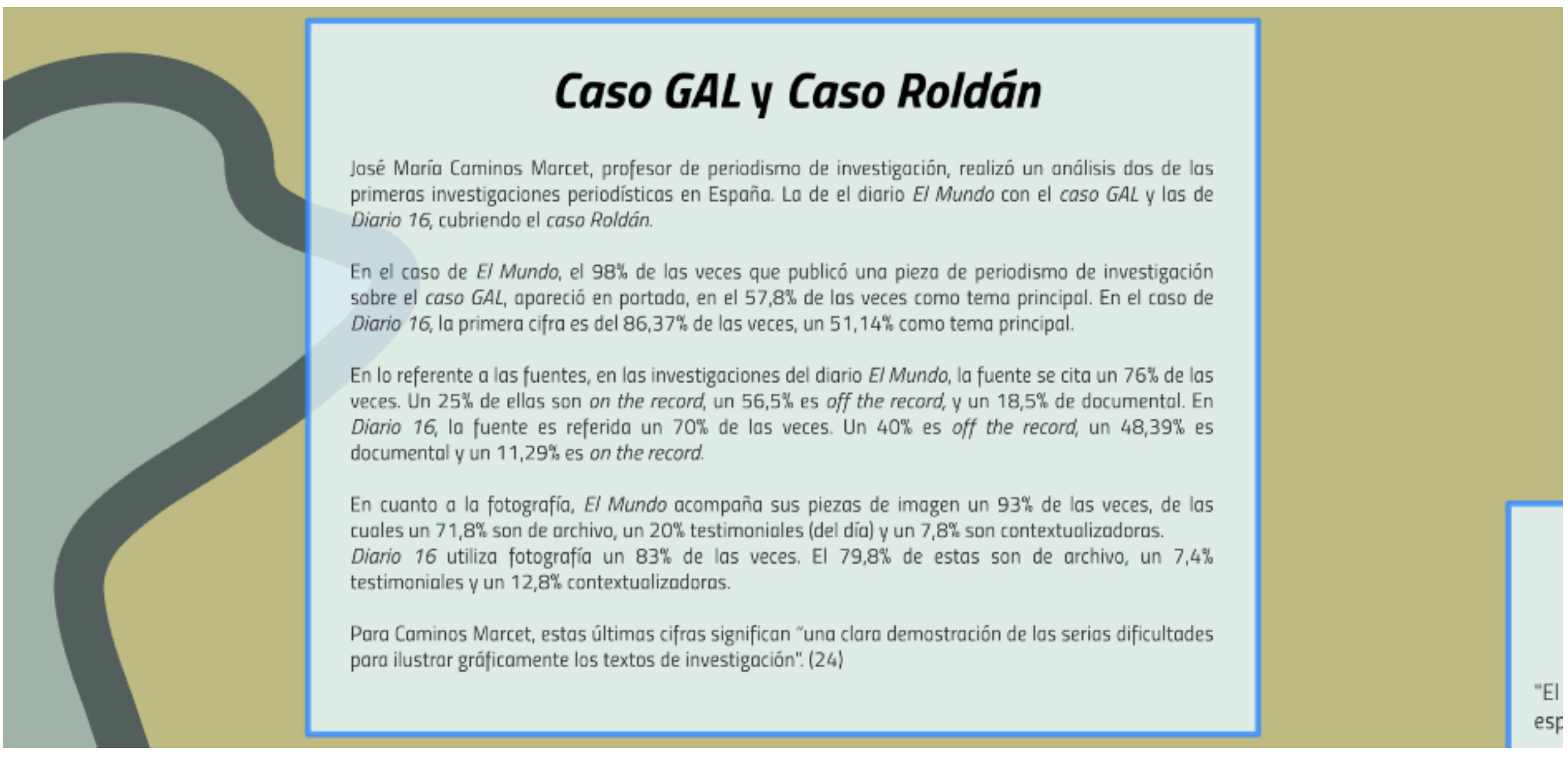





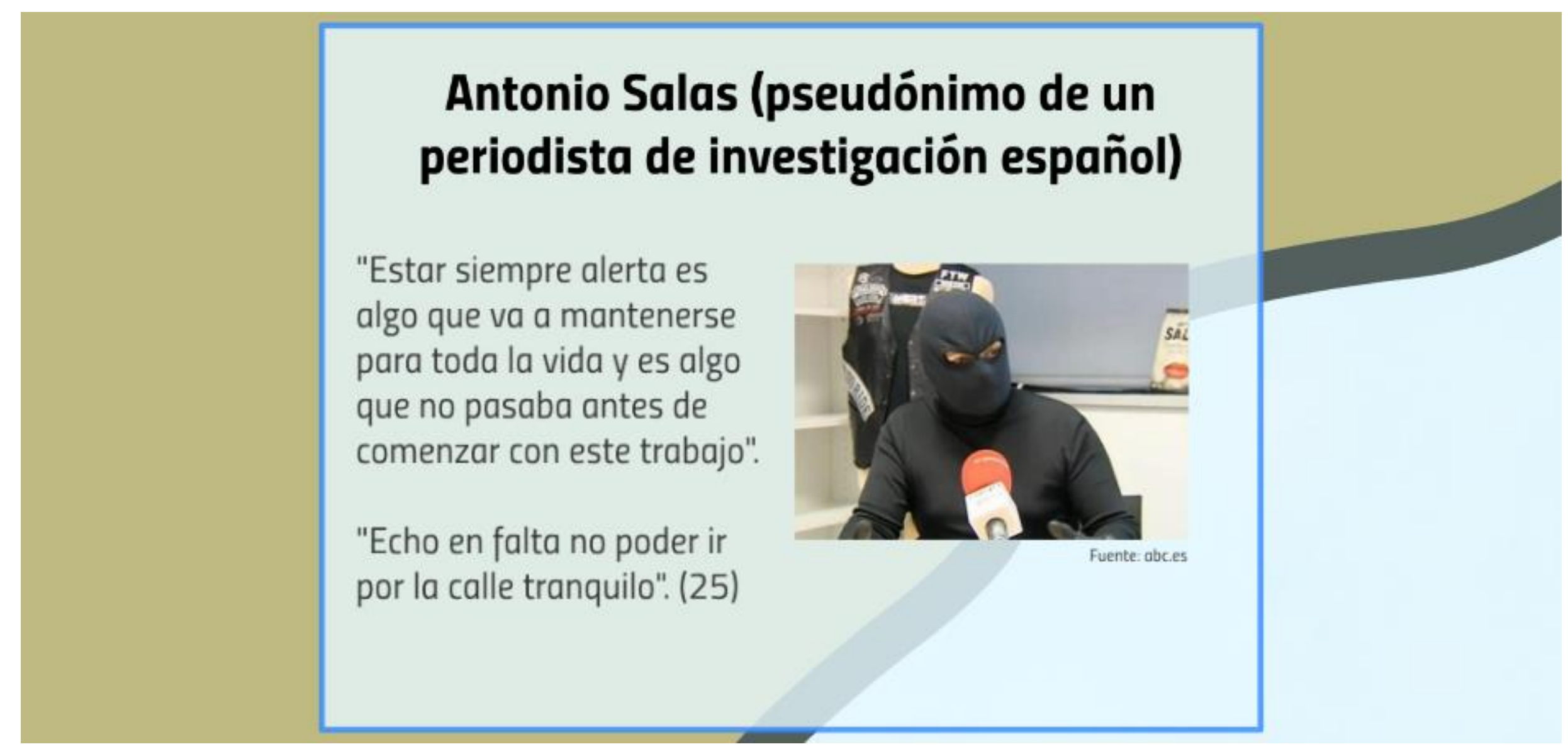





\section{Antonio Rubio (periodista)}

"El periodismo de investigación es la mejor especialización para el periodista".

"El periodismo de investigación, datos y visualización es el futuro de esta profesión".

¿Cree que el periodismo de investigación es una buena opción tal y cómo está el panorama laboral en la profesión?

La mejor. Es la especialización, el elemento diferenciador, el valor añadido. Pero para hacer Periodismo de Investigación hay que estudiar y trabajar mucho y lleva tiempo. Es una carrera de 3.000 metros obstáculos y es muy posible que al final del trayecto termines sentado en el banquillo

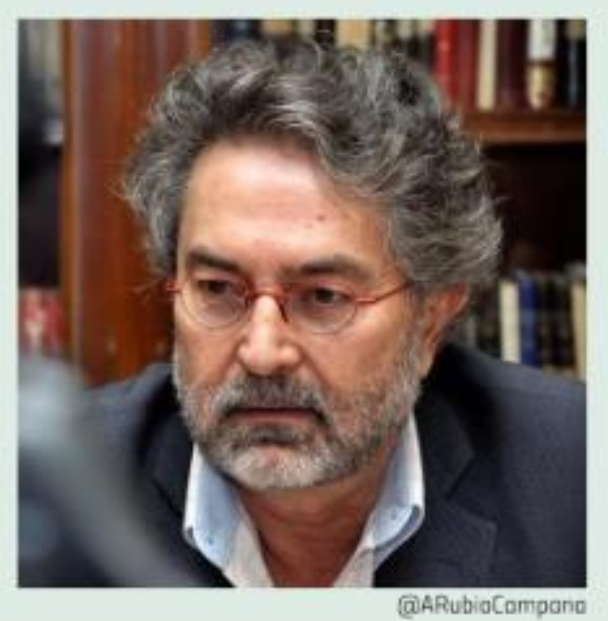

de los acusados. Los malos tienen mucho poder, pero no todo el poder. (26) 



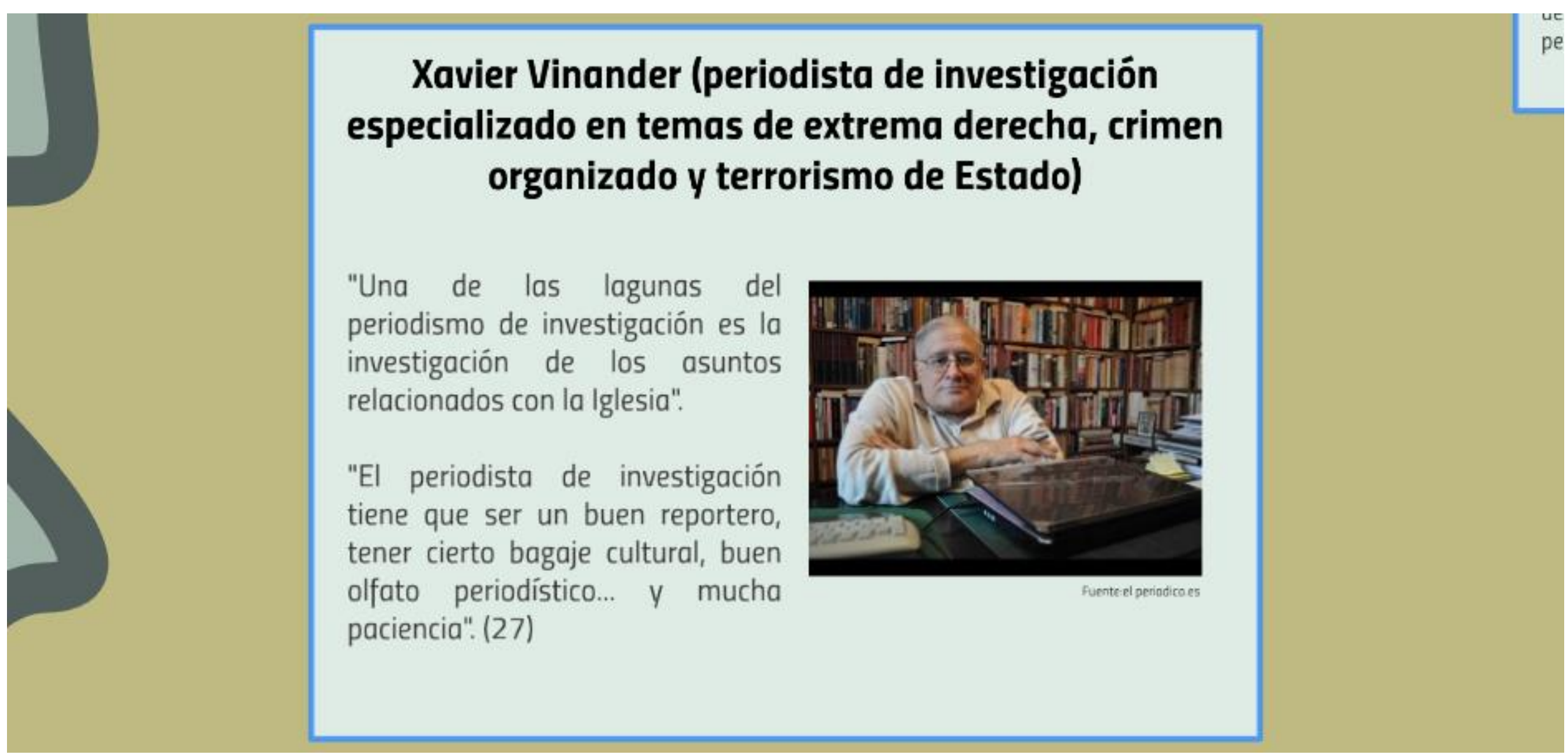





\section{Gregorio Morán (periodista de investigación)}

No recuerdo que los grandes jalones del periodismo en España estén vinculados al periodismo de investigación". (27)
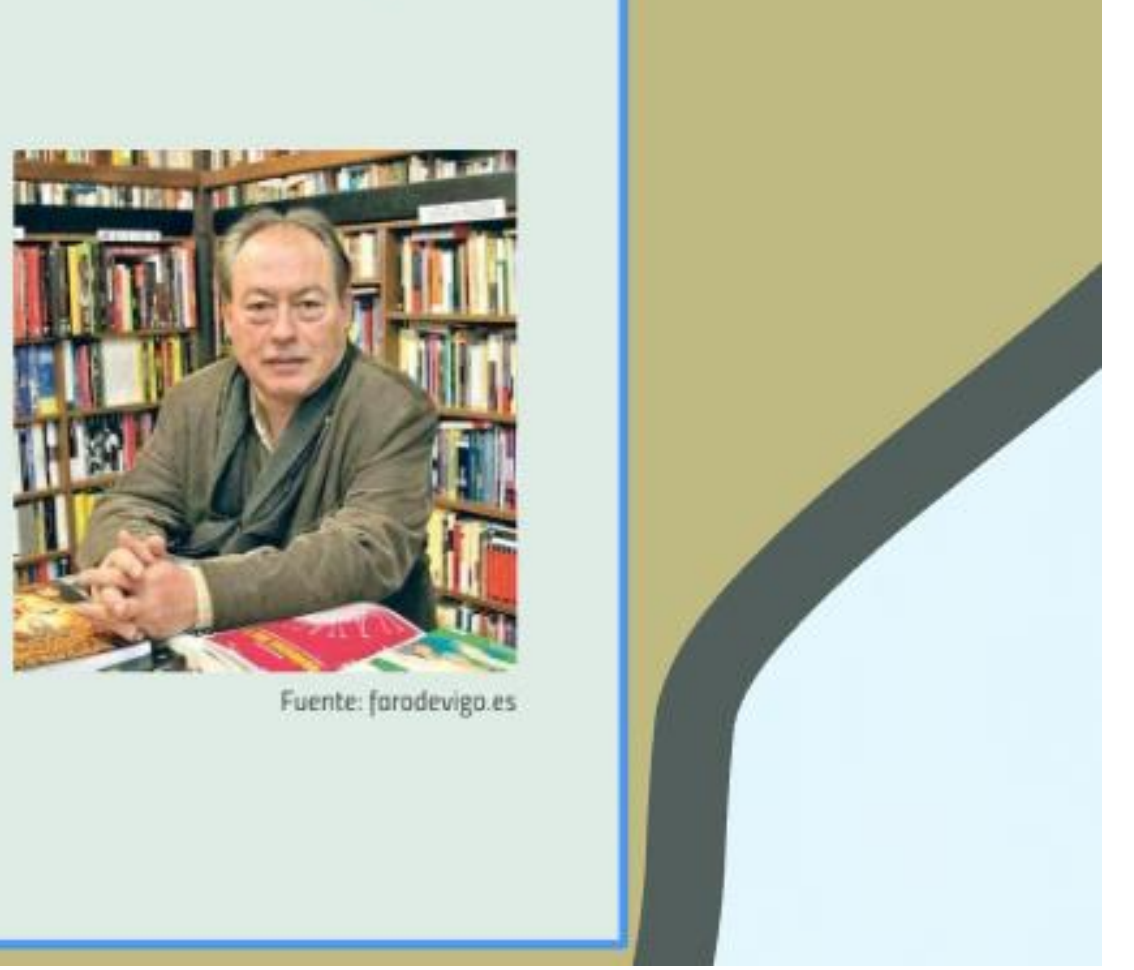




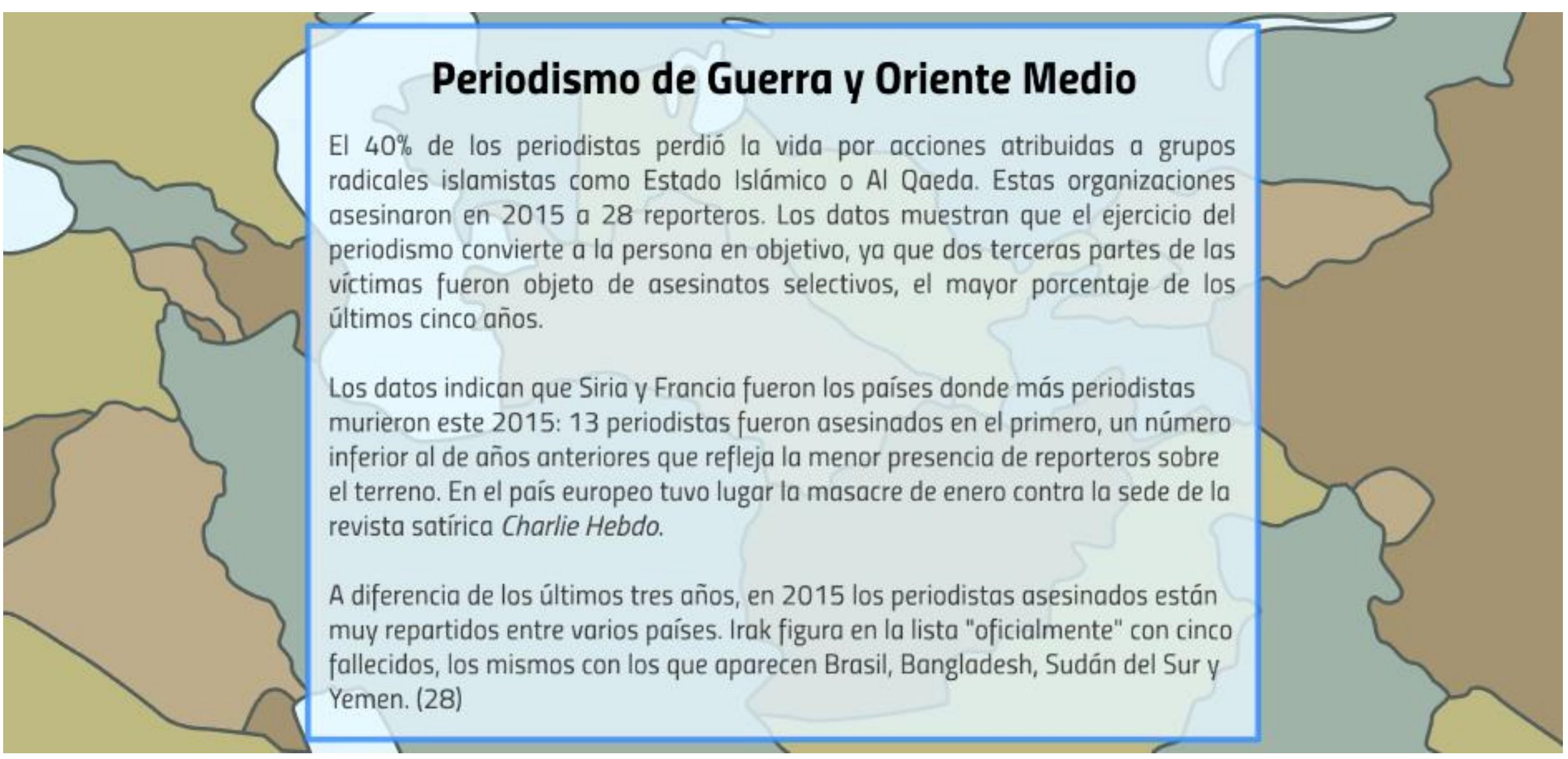





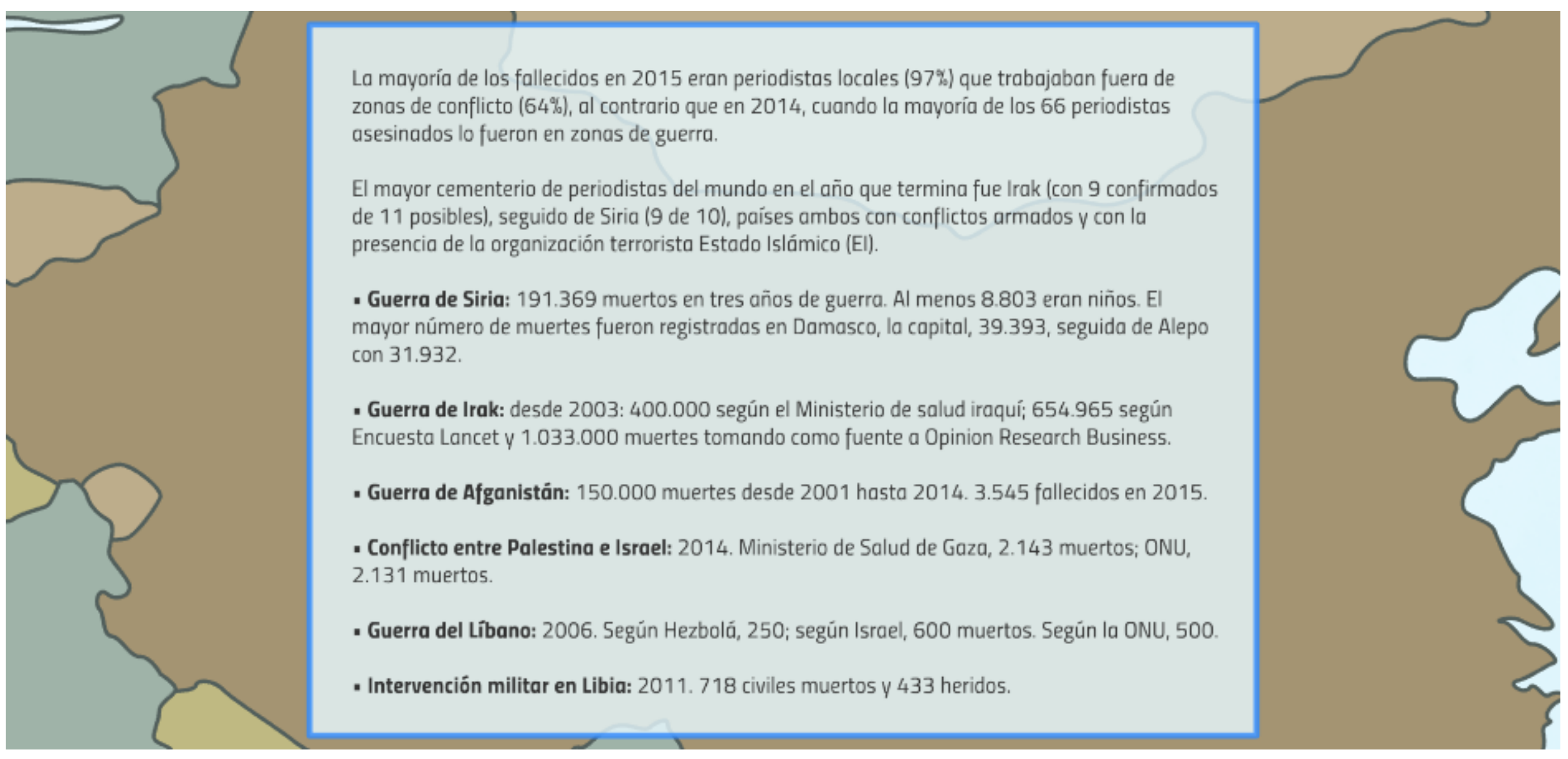





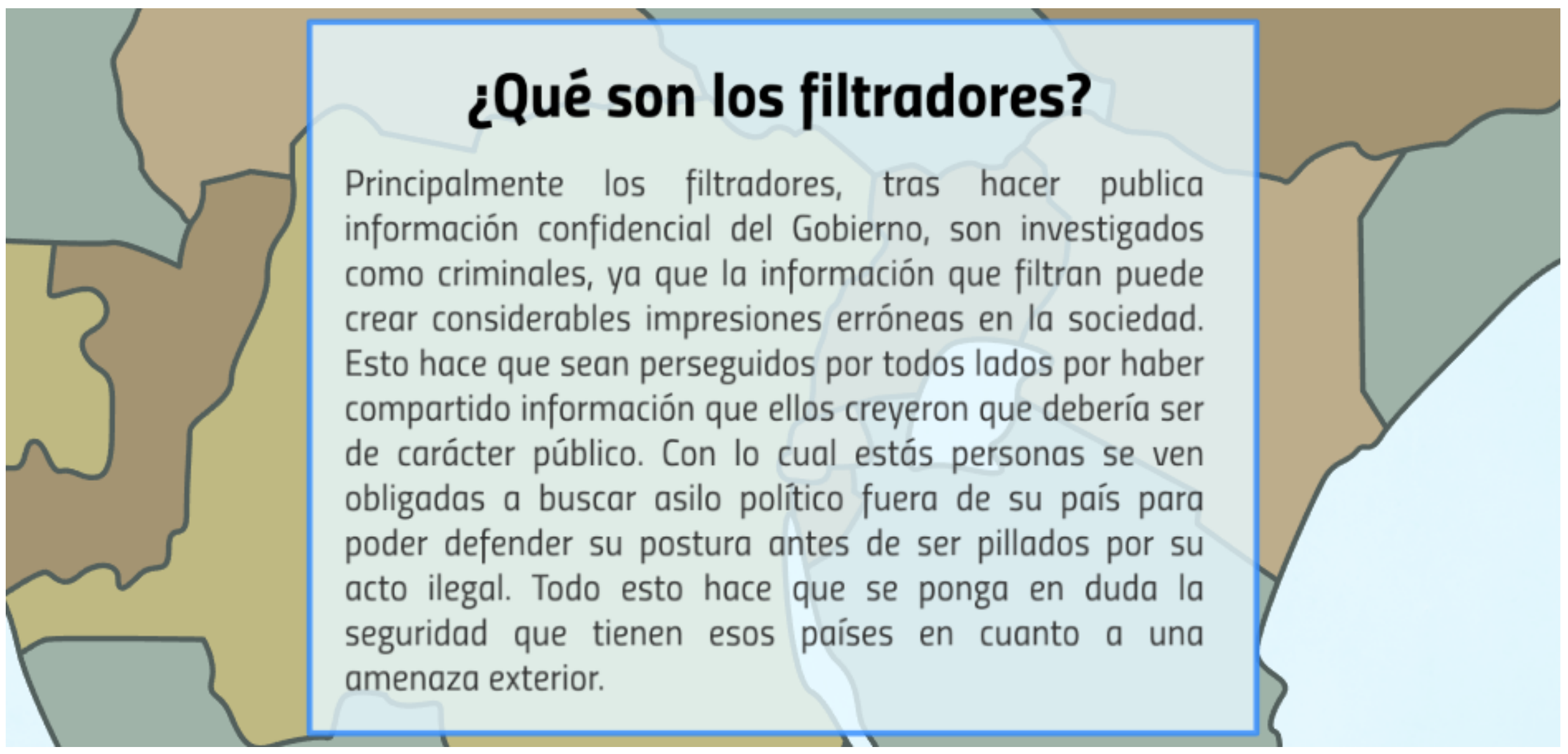





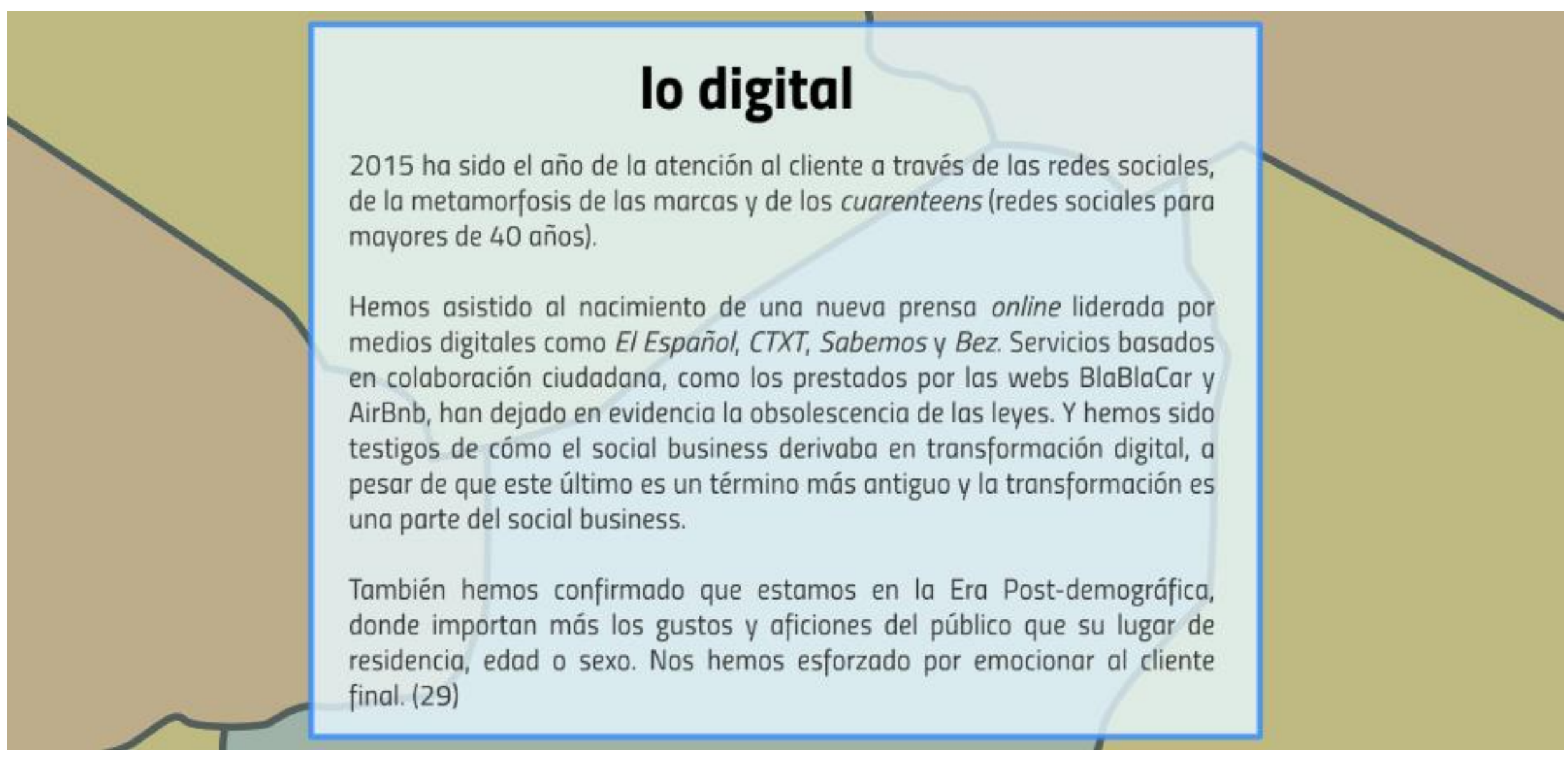





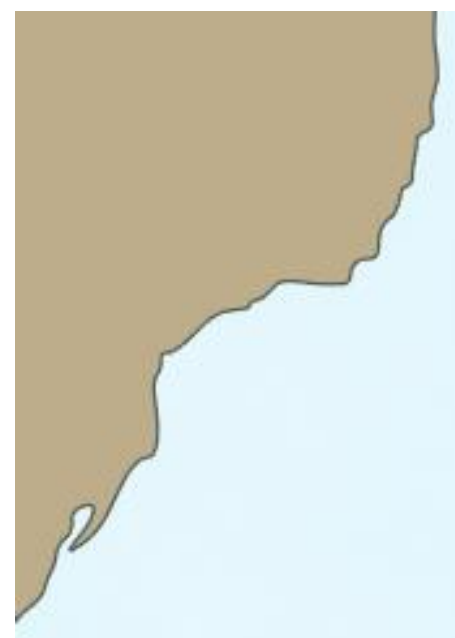

\section{Código Internacional de Ética Periodística UNESCO}

El derecho del pueblo a una información veridica que se adecue con la reaidod.

1.40 responsabilitad sacial del periodisto.

2. La integridad profesional del periodista: El papel social del periodista exige el que la profesión mantenga un alto niver de treboier en contra de ses convitciones o de reveler sus fuentes de información y tombién el derecho de participar an lo tome de decisiones en los medios de connuncorion en que esté empleado

3. Acceso y participación del pública en la información.

4. Respeto de la vida privado y de la dignidad del hombre

5. Respeto del interés público.

6. Respeto de los valores universoles y la diversidad de las cuituras: la paz, la demacracia, los derechos del hombre, el progreso social y la liberación nacional

7. El periadista participa también activamente en las transformaciones sociales orientadas hocia ing de la sociedad vecontruvve, por el dologo, a establecer un clima de en todo la paz y a justicia, la distensián, el desarme y el desarralio nacional. 



\section{Referencias}

(1) Requejo Aleman, J.L. (2011). El legado de los muckrakers, en Question, №. 29, 2011 https://perio.unlp.edu.ar/ojs/index.php/question/article/view/584/867

(2) Dader, J. (1997): Periodismo de Precisión: La vía socioinformática de descubrir noticias. Madrid: Síntesis, p. 31

(3) Ávila, A.M. (2014) Periodismo de datos: Historia y momento actual, en Perry, Felipe y Paz, Miguel (Eds.) Manual de periodismo de datos iberoamericano. Fundación Poderomedia. http://manual.periodismodedatos.org/ana-maria-avila.php

Navarro, Fernando (2010). Wikileaks: cómo destapar escándalos en Internet, en el El País, 26 de julio de 2010

https://elpais.com/internacional/2010/07/26/actualidad/1280095206 850215.html

(4) Quintana, Y. (2014). Cómo se comunicaron Snowden y Greenwald para no ser espiados por la NSA, en eldiario.es, 11 de noviembre de 2014

https://www.eldiario.es/turing/vigilancia y privacidad/comunicaron-SnowdenGreenwald-espiados-NSA 0 263174096.html

(5) Citado por Reyes, G. (1996). Periodismo de Investigación. México: Trillas, 1996, p. 257

(6) Rojas, Paola (2015), El verdadero éxito, es el que se comparte: Paola Rojas Hinojosa, en El Imparcial, http://elimparcial3.rssing.com/chan-16949770/all p397.html
(7) Lara, T. (2013) Periodista mexicana vive en exilio tras denunciar corrupción en Pemex: Entrevista con Ana Lilia Pérez, en Blog periodismo en las américas, 3 de abril de 2013 https://knightcenter.utexas.edu/es/blog/00-13419-periodista-mexicana-vive-enexilio-tras-denunciar-corrupcion-en-pemex-entrevista-con-a

(8) Crusset, P. (2012). Nuria Piera, Periodista/Productora del programa de investigación Nuria, Santa Domingo Times, número 52

(9) Ávila, A.M. (2014) Periodismo de datos: Historia y momento actual, en Perry, Felipe y Paz, Miguel (Eds.) Manual de periodismo de datos iberoamericano. Fundación Poderomedia. http://manual.periodismodedatos.org/ana-maria-avila.php

(10) CNP (2016). CNP ante la violación de los derechos humanos en Venezuela, en cnpven.org, 1 de junio de 2016. http://www.cnpven.org/articulos/colegio-nacional-deperiodistas-ante-la-violacion-de-los-derechos-humanos-en-venezuela

(11) Colprensa, (2014), Colombia, un país peligroso para ejercer el periodismo, en La Patria, 1 de febrero 2014. http://www.lapatria.com/audiencia-caso-orlandosierra/colombia-un-pais-peligroso-para-ejercer-el-periodismo-54118

(12) Semana (2016). "En los medios hay demasiada opinión y poca información": Juanita León, en Semana, 27 febrero de 2016.

https://www.semana.com/nacion/articulo/flip-juanita-leon-habla-de-polemicas-con-lalibertad-de-prensa/463038 
(13) Vargas, E. (2011). ¿Qué está pasando con el periodismo de investigación en el Perú?, en clasesdeperiodismo.com, 15 de marzo de 2011.

http://www.clasesdeperiodismo.com/2011/03/15/\%C2\%BFque-esta-pasando-con-elperiodismo-de-investigacion-en-el-peru/

(14) Pontificia Universidad Católica del Perú (2012). "En el Perú no se hace investigación periodística porque es costosa y trae consecuencias", en pucp.edu.pe https://www.youtube.com/watch?v=Ha G0bZ83jQ

(15) Contreras, P. (2017). Fabiola Torres de Ojo Público: “Nos encanta asumirnos como un laboratorio para el periodismo de investigación", en Puro periodismo, 3 octubre 2017 http://www.puroperiodismo.cl/?p=28466

(16) Gutiérrez Silvestre, W. (2013). Entrevista a Ángel Páez sobre Periodismo de Investigación, en Universidad Jaime Bausate y Meza "7c"

https://www.youtube.com/watch?v=smhDIrgwYa4

(17) Foro de Periodismo Argentino (2006). Código de Ética de FOPEA. http://www.fopea.org/etica-y-calidad/codigo-de-etica-de-fopea/

(18) Morales Peña, C. (2016). Daniel Santoro: “Hay un relato para estigmatizar a la prensa que investiga al poder", en El Deber, 22 de mayo de 2016

http://eju.tv/2016/05/daniel-santoro-relato-estigmatizar-la-prensa-investiga-al-poder/

(19) Zommer, L. (2013). Más preguntas, menos impunidad, en TEDxAvCorrientes 2013, 17 de octubre de 2013 https://www.youtube.com/watch?v=Tl1JNMFSerE

(20) Reporteros sin Fronteras (2016). Clasificación mundial 2016 de la Libertad de Prensa. La paranoia de los dirigentes frente a los periodistas, en rsf.org, 20 de abril de 2016 https://www.rsf-es.org/news/clasificacion-mundial-2016-de-la-libertad-deprensa-la-paranoia-de-los-dirigentes-frente-a-los-periodistas/

(21) Pérez Reverte, A. (2015). Periodismo agredido, en El Mundo, 22 de septiembre de 2015.

http://www.elmundo.es/opinion/2015/09/22/56018a92268e3e55548b45a0.html
(22) Cordero, N. (2016). Los papeles de Panamá y el papel de la prensa independiente: el 'making of, en El Confidencial, 11 de abril de 2016

https://blogs.elconfidencial.com/espana/caza-mayor/2016-04-11/los-papeles-depanama-y-el-papel-de-la-prensa-independiente-el-making-of 1181507/

(23) Klein, D. (2001). El papel del periodismo de investigación en la sociedad democrática, en Razón y Palabra, número 22

http://www.razonypalabra.org.mx/anteriores/n22/22 dklein.html

(24) Caminos Marcet, J.M. (1997). Periodismo de investigación. Teoría y práctica. Editorial Síntesis. https://desocultar.files.wordpress.com/2011/07/documento-19caminos-marcet.pdf

(25) Sanz Ezquerro, David (2015). El trabajo de un reportero infiltrado, Antonio Salas, periodismo sin nombre, en El Mundo, 4 de noviembre de 2015.

http://www.elmundo.es/television/2015/11/04/5639114322601d93658b45cf.html

(26) 233 grados (2013). Antonio Rubio: 'El periodismo de investigación es la mejor especialización para el periodista', en 233grados.com, 23 de septiembre de 2013

http://233grados.lainformacion.com/blog/2013/09/antonio-rubio-el-periodismo-deinvestigaci\%C3\%B3n-es-la-mejor-especializaci\%C3\%B3n-para-el-periodista.html

(27) Díaz Güell, L. (2003). Periodismo y periodistas de investigación en España, 19752000: Contribución al cambio político, jurídico, económico y social. (Tesis doctoral). https://biblioteca.ucm.es/tesis/inf/ucm-t27114.pdf

(28) La silla rota. (2015). Yihadistas, autores del $40 \%$ de crímenes contra periodistas en 2015, en La silla rota, 29 de diciembre de 2015.

https://lasillarota.com/mundo/yihadistas-autores-del-40-de-crimenes-contraperiodistas-en-2015/100345

(29) Rivera, D. (2015). Tendencias en Comunicación y Marketing 2016: en busca de marcas más inesperadas, virales y sociales, 20 de octubre de 2015 https://agencia.best/blog/tendencias-comunicacion-marketing-2016 